\title{
LOS BAÑOS EXTRAMUROS DE SAN SEBASTIÁN *
}

\author{
Jean Passini, Juan Manuel Rojas Rodriguez-Malo \\ y J. RAMÓN VILLA
}

\section{INTRODUCCIÓN}

Dentro del trabajo sobre el urbanismo de la ciudad de Toledo a finales del siglo xv, apoyándose en un documento ${ }^{1}$ del Cabildo de la Catedral de Toledo, J. Passini ha intentado localizar un lugar mencionado bajo el título de Las Bóvedas. Desde el Barrio de los Canónigos (J. Passini, J.-P. Molénat, 1995) ha buscado en dirección al Tajo, hasta observar, al sur de la carrera de San Sebastián, un grupo de casas recientemente construidas, junto a un edificio en ruinas ${ }^{2}$. Además, a unos cien metros al noroeste J. M. Rojas tuvo la oportunidad de excavar, entre 1988 y 1989 , un conjunto de estructuras que sucesivamente fueron revelando la existencia de una casa, unas tenerías ${ }^{3}$, y finalmente un baño islámico. Como consecuencia de una reflexión común J. Passini, J. M. Rojas y J. Villa-González han deducido que dentro del edificio en ruinas y abovedado están en presencia de un baño bastante bien conservado.

La comparación de estos dos baños reveló unos aspectos poco co-

* La parte 2 (el baño de San Sebastián de Yuso) es original de J. Passini (CNRS UMR 5648 Lyon); la parte 3 (el baño de San Sebastián de Suso) es original de J. M. Rojas Rodríguez-Malo y J. Ramón Villa González.

1 Libro de medida de los edificios que pertenece al capítulo de la Catedral de Toledo dentro de la ciudad. «Libro de las casas mesones e bodegas tiendas almaçerías corrales carnesçerias e solares que los sennores Deán e Cabildo de la Santa Iglesia de Toledo han e tienen en esta dicha çiudad intramuros e de lo que rinden en cada anno...., Archivo de Obras y Fábrica (=OF-356). J. Passini y J. P. Molénat están preparando una publicación de este documento.

2 Este edificio coincide con una parte del que menciona Porres Martín-Cleto, J. (1988), t. III, p. 1421: «Recientemente (en 1973) se descubrieron al pie de San Sebastián y cerca ya del río, las ruinas de un antiguo edificio, posiblemente una puerta de Abadaquín o quizá restos de las famosas clepsidras de Azarquiel.»

3 En 1605 se dice que "los curtidores de las tenerías tienen su trato y casas cerca del río... entre los molinos del Hierro y adelante de los de San Sebastián». Pisa, F. de (1605). 
nocidos de los baños toledanos. En primer lugar, en los dos baños mencionados se observa todavía el arco de medio punto en el cual se alojaban el fogón y el caldero. El hipocausto es también visible en los dos baños. Además el estudio arqueológico da a conocer el sistema de salida del aire por las chimeneas, y que el hipocausto no llega a la sala intermedia. Por lo que se refiere a las estructuras, se encuentran en los dos baños uno o dos ábsides de planta rectangular. Este tipo de espacio no estaba mencionado en los baños toledanos islámicos descritos hasta el momento (Amador de los Ríos, R., 1905; González Simancas, M., 1929; Delgado Valero, C., 1987). Por estas razones ha parecido útil publicar conjuntamente estos dos baños.

Había que cuestionarse si estos baños coincidían con unos ya mencionados en la documentación medieval. Se sitúan al mismo tiempo al sur de la iglesia de San Sebastián y fuera de las murallas (fig. 1). Uno está al noroeste del antiguo molino de la Torre ${ }^{4}$, el otro al noreste del mismo. El sitio de uno de los dos es muy cercano a la puerta de Abadaquín ${ }^{5}$ (fig. 1). En la litografía de Guesdon (1854-1856), se localizan los edificios que se elevan sobre los baños. Así se puede apreciar la existencia, en la segunda mitad del siglo xIx, de un barranco que los separa y que, actualmente, ha sido rellenado. $\mathrm{Al}$ oeste del barranco se localiza la zona de las tenerías, y al este la de la Alcurnia ${ }^{6}$. No se ha podido encontrar ninguna referencia respecto a estos dos baños. No pueden coincidir ni con el baño de San Sebastián citado en 1243, el cual está intramuros como lo concluye Delgado Valero (1987), ni con el baño del Fierro ${ }^{7}$ aunque es extramuros. Debido a que los dos baños se encuentran en las cercanías de la iglesia de San Sebastián ha parecido conveniente darles el nombre de «Baños de San Sebastián", calificando "baño de San Sebastián de Suso" el baño más cerca de la iglesia, "baño de San Sebastián de Yuso», el más próximo al río.

\footnotetext{
4 «El molino de la Torre son al pie de la cuesta alta por donde se baja al río de la iglesia de San Sebastián. Dio les este nombre una torre que labro cerca de ellos el Arzobispo dó Rodrigo, que hoy no esta acabada de caer.» Pisa (1605).

5 La localización de la puerta de Abadaquín ha sido, hasta el momento, controvertida (González Palencia, A., 1930). A fin de aclarar su situación hemos intentado recogerla comparando los planos del Greco (1606-1614), de Coello (1849-1850), la perspectiva de Guesdon (1854-1856) y el catastro de Toledo al empezar el siglo xx. La situamos (fig. 1) ligeramente al oeste del Alhandaque, frente a la iglesia de San Sebastián.

6 Pisa, F., 1605, 1, XIII, 25: «No es justo passar en silencio el sitio de la huerta, que fue famosa en esta ciudad, llamada de la Alcurnia, en aquel agrande arenal que esta a la ribera del Tajo, cerca de los Tintes..."

7 El problema de la localización del baño del Hierro estará analizado en una publicación en preparación con J. P. Molénat sobre "Los baños de Toledo".
} 

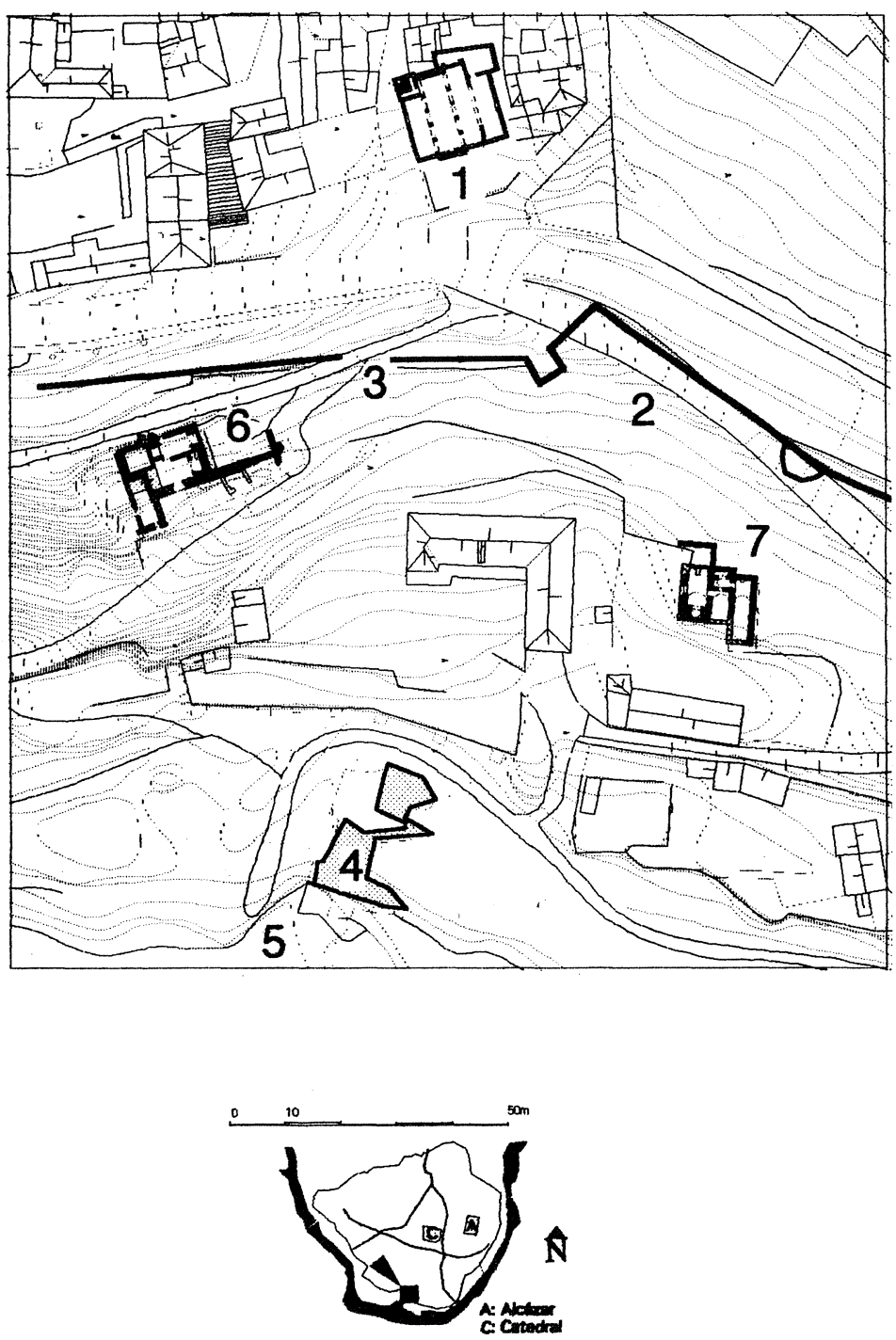

LOCALIZACION

Figura 1. Plano de situación de los baños de San Sebastián. 1. Iglesia de San Sebastián; 2. Trazado de la muralla; 3. Puerta de Adabaquín (hipótesis); 4. Molino de la Torre (de Moya); 5. Río Tajo; 6. Baño de San Sebastián de Suso; 7. Baño de San Sebastián de Yuso 


\section{El baño de San Sebastián de Yuso}

$\mathrm{Al}$ sur de la muralla de la ciudad, a unos cien metros de la iglesia de San Sebastián, y al noroeste del molino de San Sebastián, en una pendiente abrupta muy retocada en los últimos años, se mantiene un edificio arruinado ${ }^{8}$ en el cual se notan tres salas abovedadas (lam. 1), objeto de nuestra atención.

\subsection{Estado actual de las bóvedas al noreste del molino de San Sebastián}

Tres bóvedas paralelas y contiguas, orientadas de norte a sur, persisten todavía aunque arruinados sus muros sur. Actualmente se entra con dificultad en la bóveda del poniente por un hueco abierto en el muro oeste. Atravesando dos salas se llega a la sala oriental pegada a la roca y a un aterrazamiento.

Estas salas, de plantas rectangulares (fig. 2), tienen como medidas, respectivamente del este al oeste, 2.90, 3.17 y 3.61 metros de ancho; $11.40,7.70$ y 8.24 metros de largo; 3.75, 3.53 y $4.53 \mathrm{~m}$ de altura. Están cubiertas con bóveda de medio cañón realizada en ladrillo, protegida al exterior por una capa de mortero.

Por una puerta, situada en el extremo norte del muro oeste, se pasa de la sala este a la sala intermedia. El espesor del muro común a estas dos salas es de $0.70 \mathrm{~m}$. Sobre el suelo se aprecia una franja de $0,50 \mathrm{~m}$ de anchura constituida por piedras regulares y ajustadas (fig. 3). Insertada sobre esta base se nota una cinta de piedras rectangulares (fig. 3) que parece recorrer todo el perímetro de las dos salas. Una puerta (fig. 2) de $0.91 \mathrm{~m}$ de largo y $2 \mathrm{~m}$ de altura la divide en dos cuartos de dimensiones desiguales. En el pequeño cuarto norte, un arco de medio punto, de $1.71 \mathrm{~m}$ de largo y $2 \mathrm{~m}$ de alto, aísla una pequeña camarilla, cuya profundidad es de $0,87 \mathrm{~m}$, cubierta de bóveda de medio cañón perforada por un tragaluz. En el muro poniente del cuarto grande una puerta comunica con la sala contigua.

En el extremo sur de esta sala, un gran arco de herradura (fig. 5) separa un ábside de planta cuadrada cubierto con bóveda de medio cañón. El

8 Porres Martín-Cleto, J. (1988), t. III, lámina 426, 1257. Este edificio en ruinas aparece en una fotografía la cual tiene la leyenda siguiente "Restos del molino de San Sebastián y ruinas de un edificio árabe (¿clepsidras de Azarquiel?) entre la orilla y las Carreras, al pie de Abadaquín». 


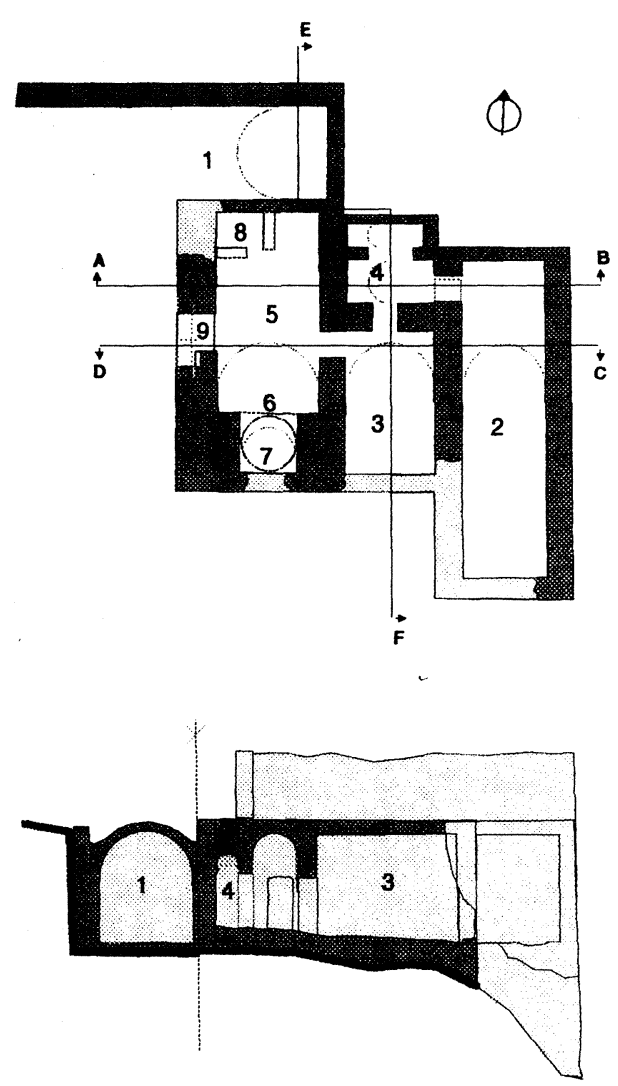

Secclón E-F

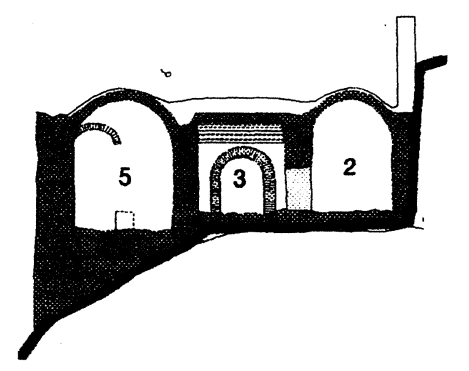

Section A-B

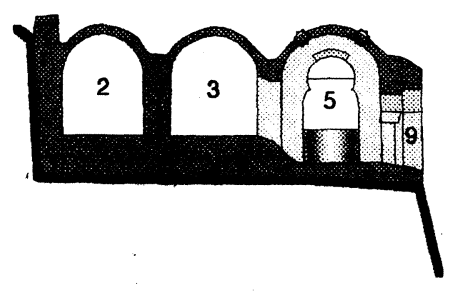

Sección C-D

$012 \quad 4 m$

Figura 2. Plano y secciones de las bóvedas de San Sebastián de Yuso: estado actual: 1. Sala en ruina; $2,3,5$. Salas con bóvedas de medio cañón; 4. Alcoba; 6 . Arco de herradura; 7. Ábside de planta cuadrada, 8. Alcobas; 9. Arco de medio punto. 


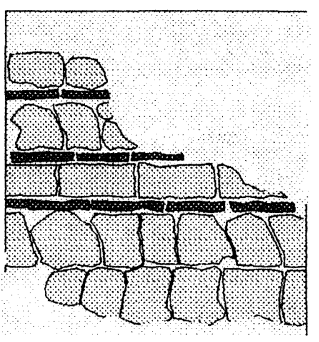

0
$50 \mathrm{~cm}$

Figura 3. Aparejo de la sala intermedia: detalle.

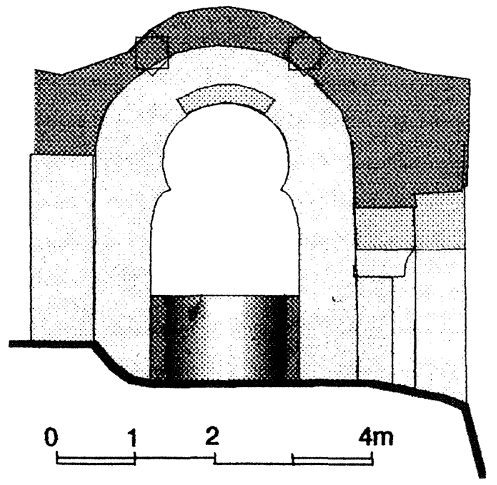

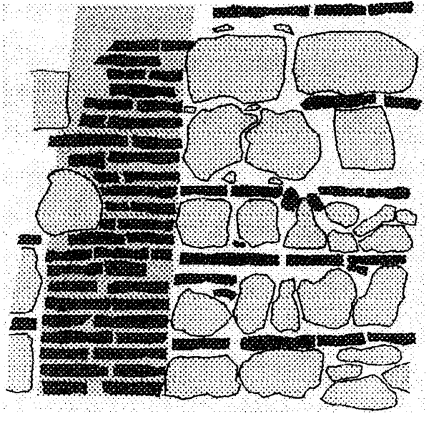

0 .
$30 \mathrm{~cm}$

Figura 4. Aparejo de la sala poniente: detalle.

Figura 5. Sala poniente: arco de herradura, elevación interior.

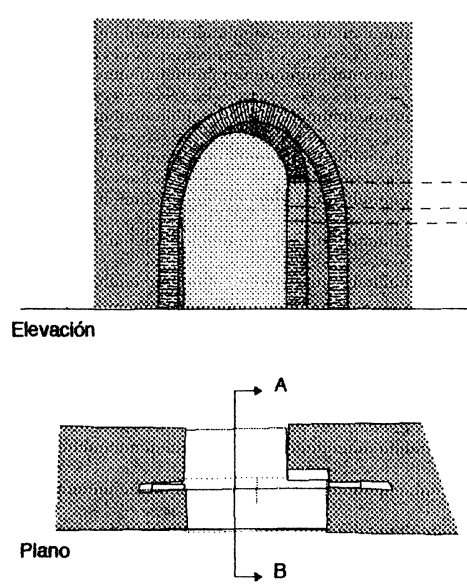

Sección A-B

Figura 6. Puerta de ladrillo en el muro poniente: 1 . dos arcos superpuestos (elevación y plano); 2. dos resaltos en el arco interior (sección).

(c) Consejo Superior de Investigaciones Científicas http://al-qantara.revistas.csic.es 


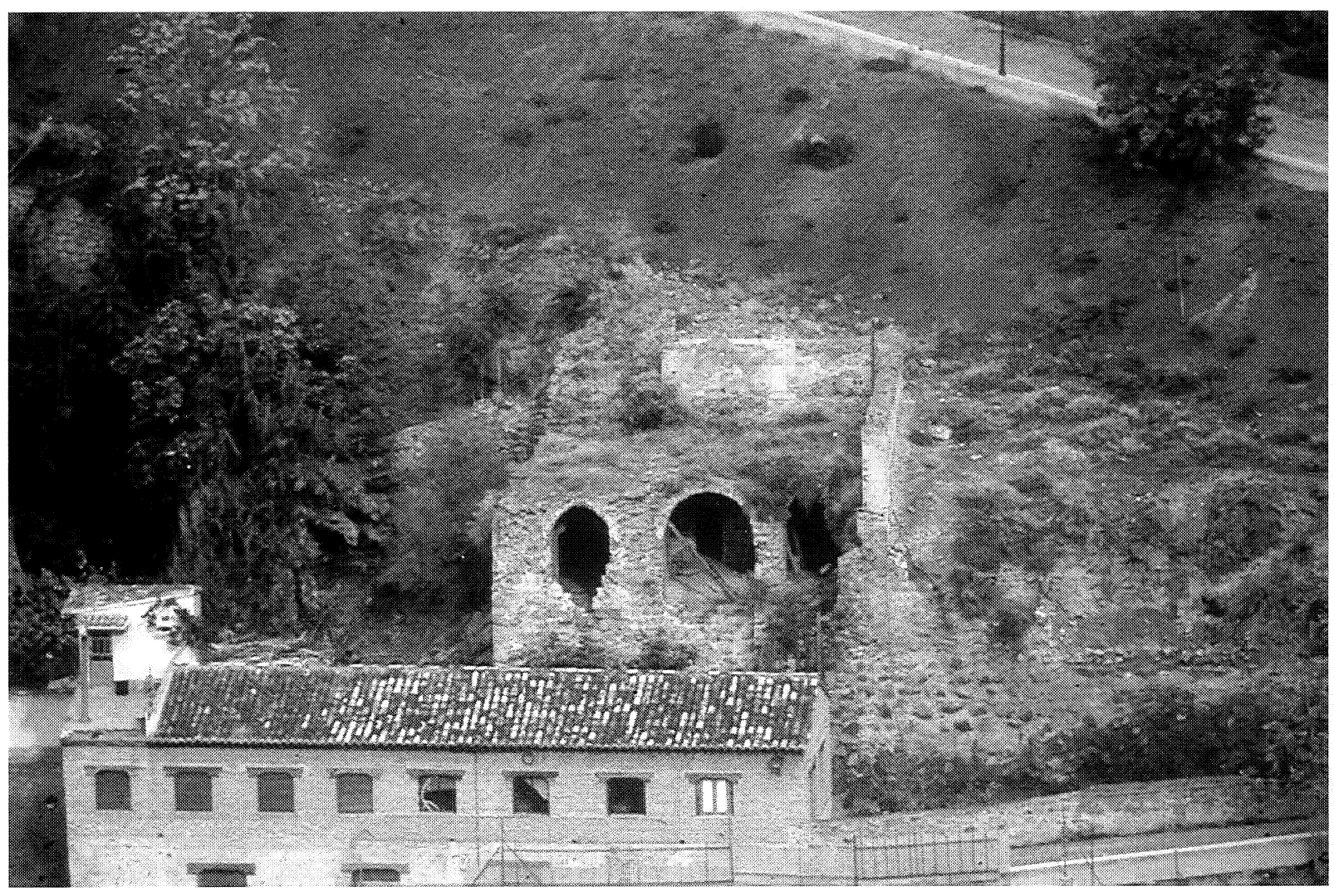

Lámina 1. Baño de San Sebastián de Yuso: visto general. J. Passini, 1995.

(c) Consejo Superior de Investigaciones Científicas

http://al-qantara.revistas.csic.es Licencia Creative Commons

Reconocimiento 4.0 Internacional (CC BY 4.0) 


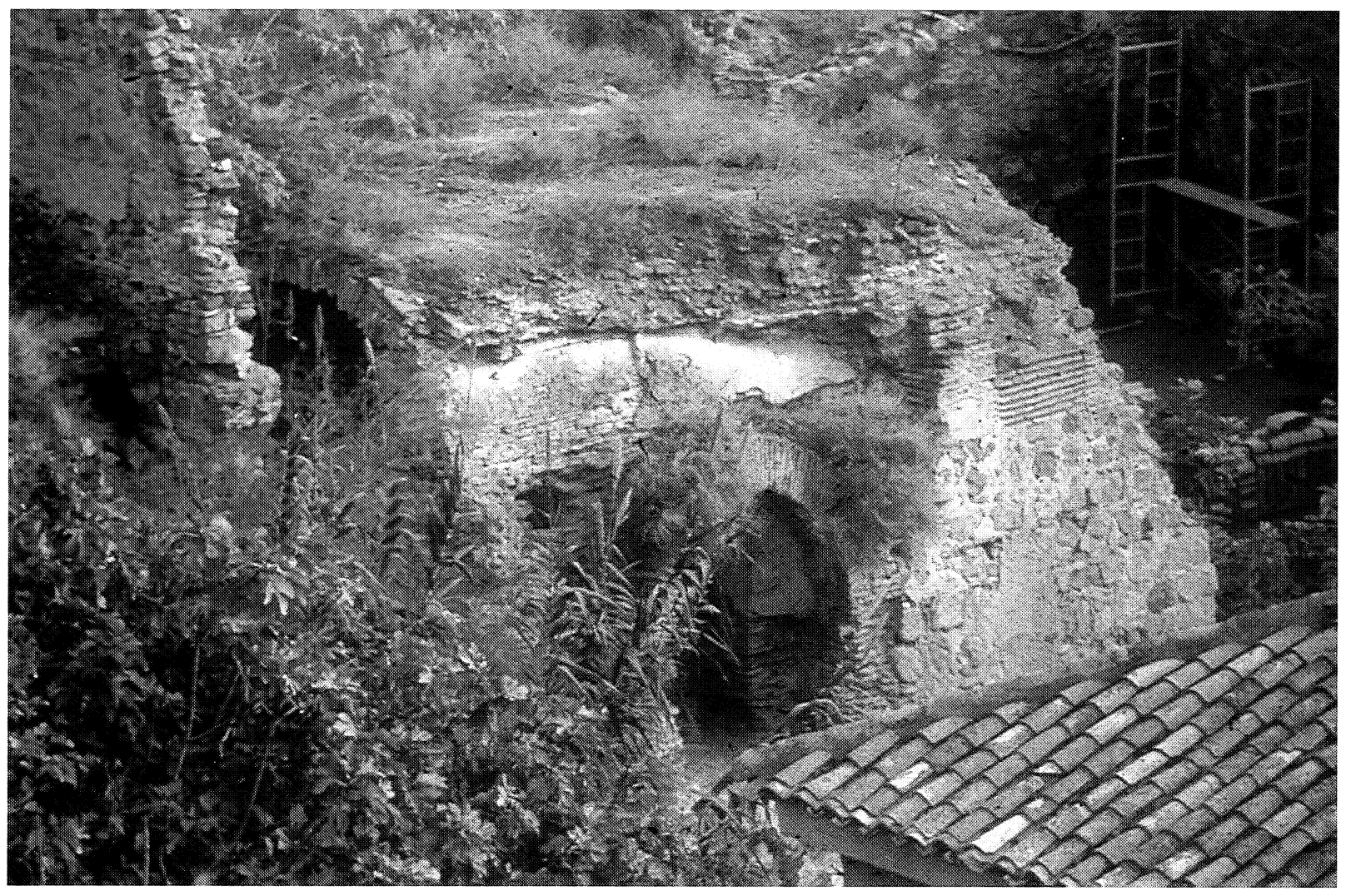

Lámina 2. Baño de San Sebastián de Yuso: vano del caldero en el muro externo de la sala del poniente. J. Passini, 1995. 


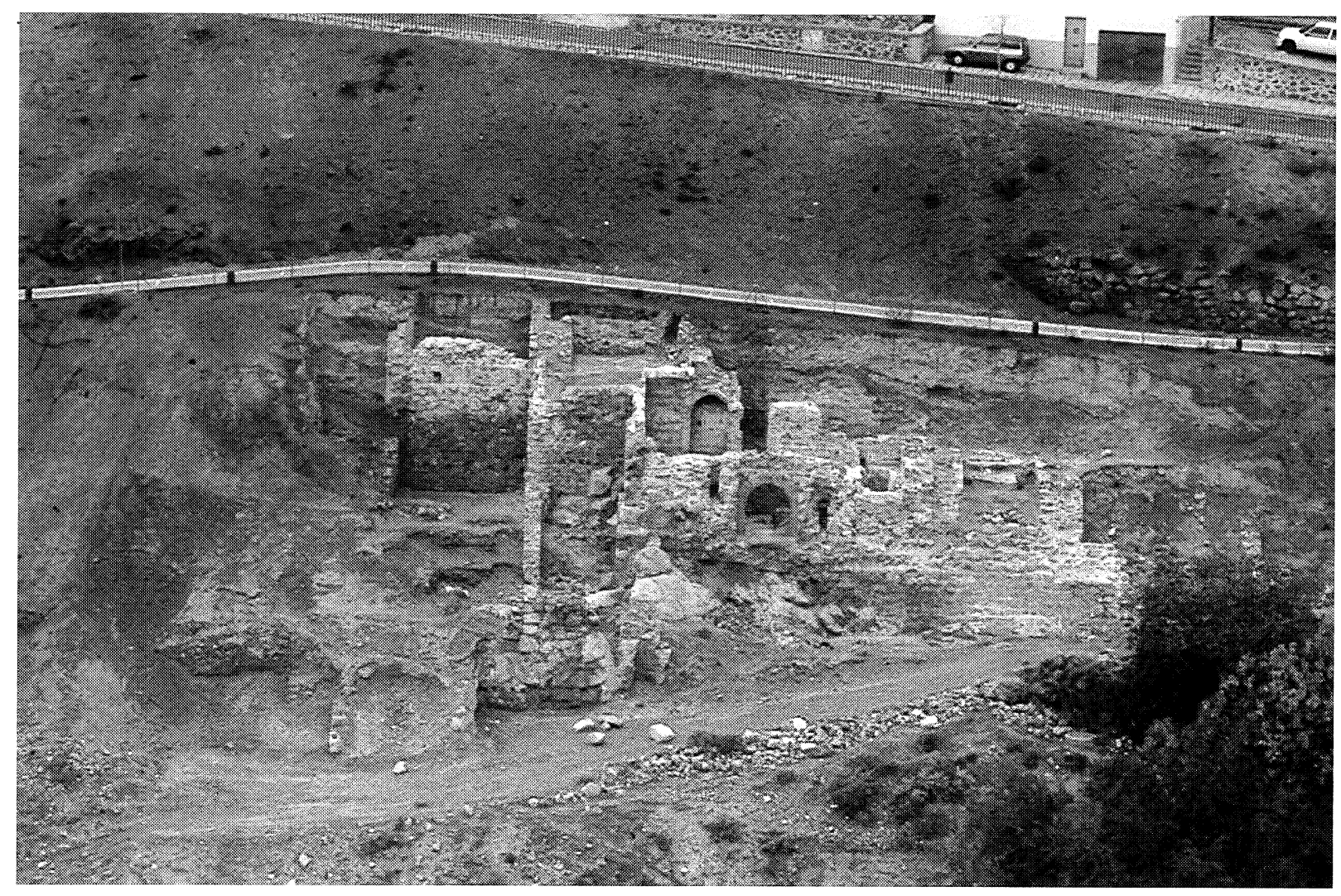

LÁmina 3. Baño de San Sebastián de Suso: vista general desde la otra orilla del río. J. Passini, 1990.

(c) Consejo Superior de Investigaciones Científicas Licencia Creative Commons

Reconocimiento 4.0 Internacional (CC BY 4.0) http://al-qantara.revistas.csic.es 


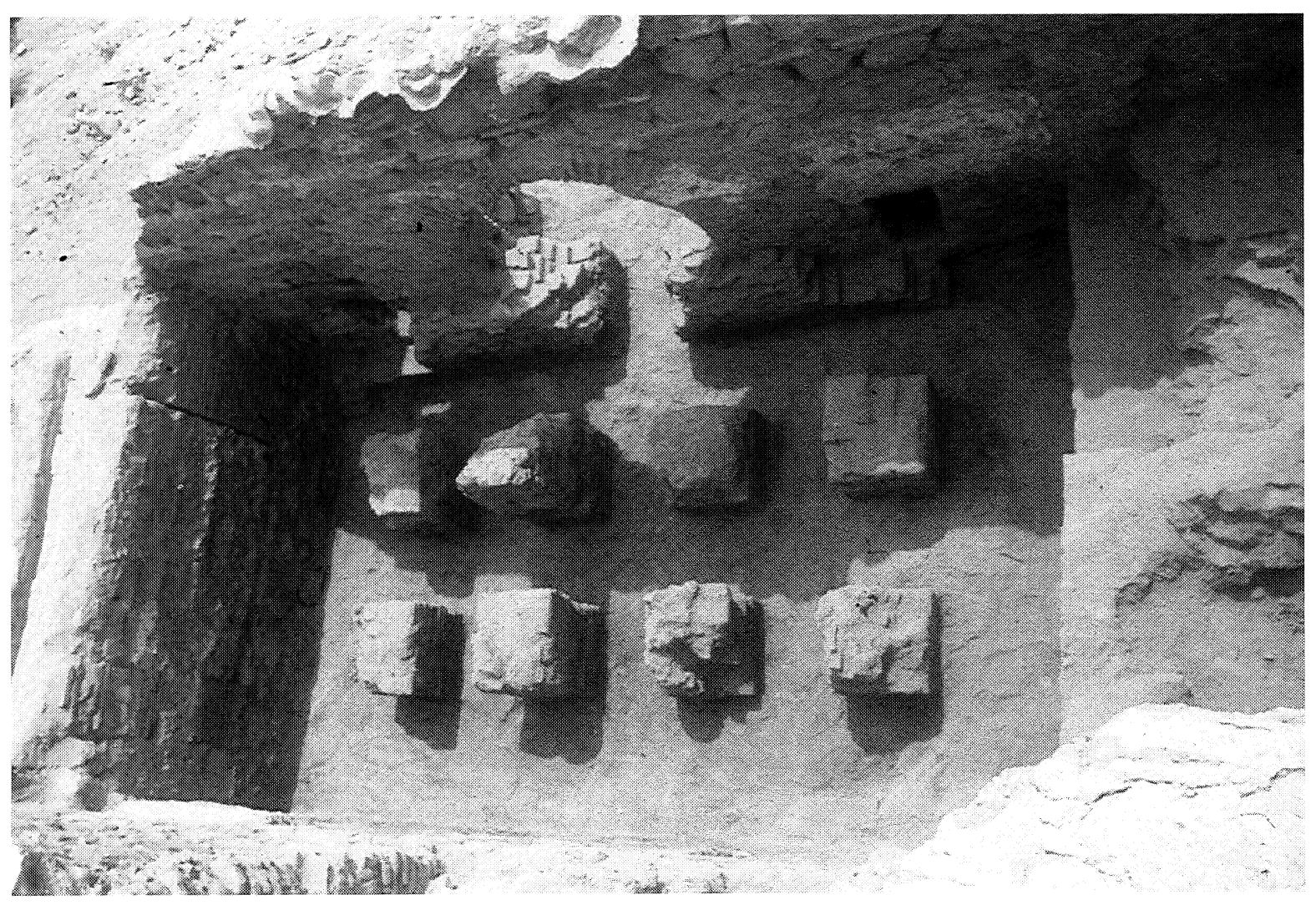

Lámina 4. Baño de San Sebastián de Suso: vista del hipocausto. J. M. Rojas, 1996.

(c) Consejo Superior de Investigaciones Científicas

http://al-qantara.revistas.csic.es Licencia Creative Commons

Reconocimiento 4.0 Internacional (CC BY 4.0) 


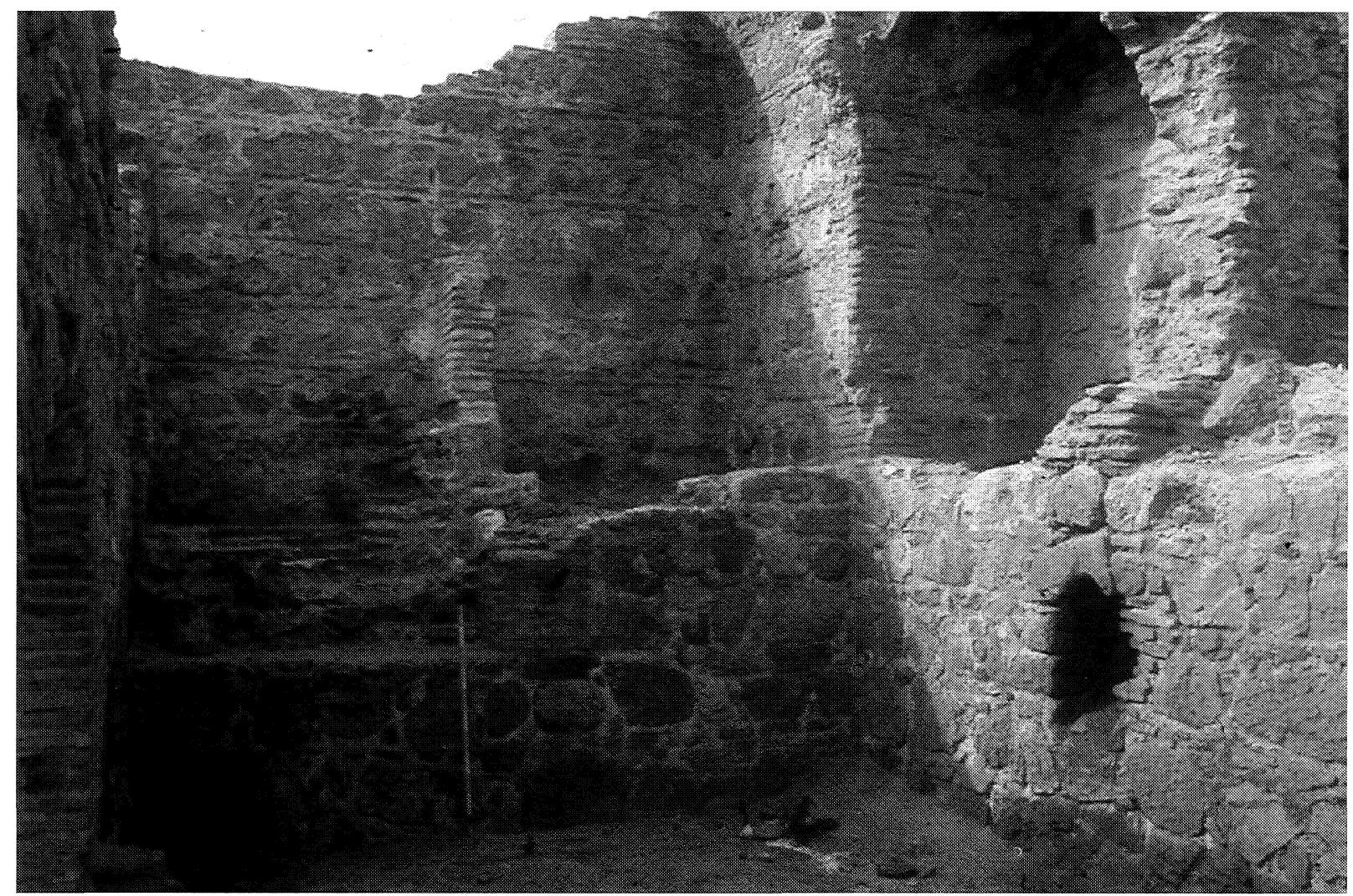

LÁmina 5. Baño de San Sebastián de Yuso: vista de las alcobas germinadas de la sala cabreriza. J. M. Rojas, 1996.

(c) Consejo Superior de Investigaciones Científicas

http://al-qantara.revistas.csic.es Licencia Creative Commons

Reconocimiento 4.0 Internacional (CC BY 4.0) 
ábside presenta en su parte inferior, sobre una altura de 1,20 m, una sección subcircular abierta, en la cual se aprecia una gran cantidad de finas capas de concreciones calcáreas. En seguida, supuestamente hasta la base del arco, se observa un aparejo muy bien hecho de mampostería encintada de $0.43 \mathrm{~m}$ en el cual las piedras están separadas por dos verdugadas completas de ladrillo de $0.09 \mathrm{~m}$. En el extremo opuesto, la bóveda de medio cañón se interrumpe a una distancia de $1.20 \mathrm{~m}$ del muro norte, sobre el cual se nota la traza de un pequeño arco de medio punto. En el nivel inferior persiste todavía un murete de ladrillo y cemento duro, perpendicular al muro norte, de $0.60 \mathrm{~m}$ de alto y también, junto al muro oeste, a menos de $1.20 \mathrm{~m}$ del muro norte, el resto de un murete arrasado. Los muros de la sala de poniente aparecen cubiertos de un revoco interrumpido sobre el muro oriental, en el área sin bóveda. En este paramento puede verse el aparejo de mampostería, que no sobrepasa $0.30 \mathrm{~m}$, encintada por una verdugada de ladrillo (fig. 4). En el nivel del final de la bóveda principal se nota el resto del pie derecho del arco de la alcoba. El espesor del muro común a la sala intermedia es de $1 \mathrm{~m}$, aunque el muro poniente es de $1.30 \mathrm{~m}$. En el grueso de este último muro, frente a la puerta de la sala intermedia, se abre un arco de medio punto, de $1.34 \mathrm{~m}$ de ancho y $2.76 \mathrm{~m}$ de alto. Este arco constituye el vano interior de una puerta fabricada con ladrillos que se observa en el exterior del muro de poniente, a este arco interior se adosa un arco exterior apuntado. En la jamba del arco de medio punto se notan dos resaltos en arco (fig. 6). Hoy esta puerta abre al vacío, por intervención humana reciente, el nivel del suelo está a unos tres metros debajo del nivel del suelo de la sala de poniente. No se puede salir, o ingresar por esta puerta. Las bóvedas de la sala del poniente están perforadas por dos filas de tres tragaluces de sección de estrella de ocho puntas, hoy ciegas.

Detrás de la sala del poniente $\mathrm{y}$, sin comunicación aparente con ella, existen los restos de una sala en ruina (fig. 2). Conserva una parte de 3.50 $m$ de lado, abovedada de medio cañón; aunque el muro norte se prolonga en dirección oeste. Sobre este muro hay unos arranques de bóveda, posiblemente de medio cañón. Esta sala se apoya al norte y al este sobre tierra o roca madre.

\subsection{Restitución del baño de Yuso}

De la descripción anterior creemos importante subrayar los puntos siguientes: 
- una sala de dirección oeste-este, sin comunicación directa con las tres salas perpendiculares a ella, y paralelas entre sí;

- al este, una sala rectangular, la más larga de todas, cubierta de bóveda de medio cañón;

- en medio, una sala rectangular dividida en dos. Cada cuarto cubierto de bóveda de medio cañón. En el cuarto pequeño tiene una pequeña alcoba;

- al poniente, una sala rectangular, abovedada de medio cañón, tiene en su extremo sur un ábside de planta cuadrada; en el extremo opuesto, aunque, en estos momentos, la bóveda de medio cañón está interrumpida, originalmente estuvo abovedado, protegiendo dos alcobas separadas de la parte central por arcos gemelos de los cuales sólo se han conservado la traza de un arco de medio punto, los muretes y una jamba;

- un arco de medio punto en el muro oeste de la sala poniente;

- el espesor de los muros es notable, particularmente el muro oeste de la sala del poniente $(1.30 \mathrm{~m})$.

Si adjuntamos que, hace unos años, existía todavía ${ }^{9}$ una canalización de agua al oeste de la sala del poniente en un área hoy destruida, podemos considerar que estas estructuras abovedadas constituyen los restos de un baño islámico "conservado, como muchos otros en España, gracias a la solidez de su construcción" (Torres Balbás, 1959). Además el plano formado por estas bóvedas responde al plano agrupado de los baños islámicos toledanos.

Las funciones de estas salas aparecen claramente (fig. 7). En la sala oriental estaba el cuarto frío (al-bayt al-barid); en la sala intermedia la templada (al-bayt al-wastāni); y por último a la sala del poniente correspondía la sala caliente (al-bayt al-sajün). En el arco abierto en el grueso muro de poniente de la sala caliente estaban sobrepuestos el horno y el caldero. Bajo el suelo de la sala caliente, actualmente destruido y más bajo que el suelo de la sala intermedia, se situaba el hipocausto. La entrada al baño no ha subsistido. Además la función de la sala pegada al norte de la sala poniente resulta desconocida.

$\mathrm{Al}$ oeste de la sala caliente estaba un cuarto de servicio y la leñera, totalmente desaparecida. No comunicaba con la sala caliente sino por medio de una abertura que permitía el paso del vapor y del agua caliente que salían del fogón y del caldero. El aire caliente saliendo del fogón circulaba

9 Información que debemos al propietario de estas bóvedas, a quien agradecemos el habernos facilitado su visita. 

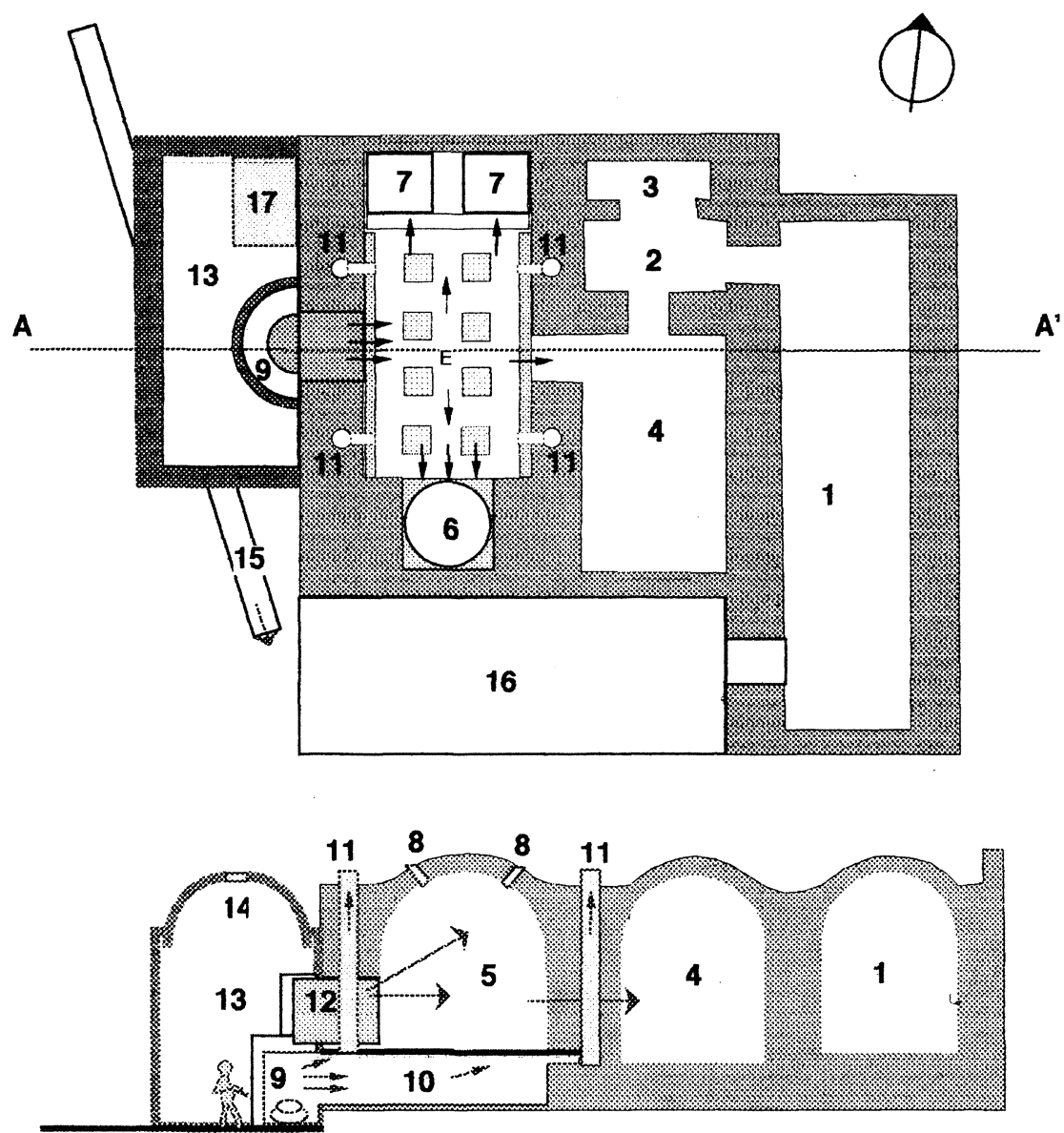

(15)

\section{Sección AA'}

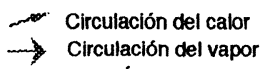

0 $5 m$

Figura 7. Baño de San Sebastián de Yuso: restitución. 1. Sala fría; 2. Sala de paso; 3. Alcoba de reposo; 4. Sala templada; 5 . Sala caliente; 6 . Pila llena de agua, tibia; 7. Alcoba; 8. Tragaluz; 9. Fogón; 10. Hipocausto; 11. Tobera; 12. Caldero; 13. Caldera (restitución); 14. Respiradero de la caldera; 15. Canal de abastecimiento; 16. Vestuario hipotético; 17. Aljibe. 
en el hipocausto, y se evacua por las chimeneas; el emplazamiento de dos de ellas es visible: una en el muro exterior, otra en el muro común a las salas caliente e intermedia. Calentaba al extremo sur la pared de la pileta de agua tibia. El hipocausto debía terminar contra el murete de las alcobas; es difícil conocer con certidumbre su altura.

La sala de dirección este-oeste ha podido tener una doble función: arquitectónica una, habitación otra. Por otro lado, creemos probable que al sur de los baños se prolongara un aterrazamiento sostenido por roca y muro, todavía visible en este momento, por lo que el vestuario se encontraría al sur (fig. 7). La destrucción del muro de la sala fría no permite verificar la comunicación con el posible vestuario. Probablemente, el vestuario cerraría con bóveda de arista, de manera semejante a la observable en el baño de Yaix; este tipo de bóveda se arruina con más facilidad que la bóveda de medio cañón.

\subsection{Discusión}

A continuación vamos a tratar de la conformidad de los elementos de este baño con los baños islámicos de Toledo tomando como referencias los datos de los baños de Yaix y del Pozo Amargo y la comparación con el baño de Suso ${ }^{10}$; las referencias con los textos y por fin la evolución de este baño desde el siglo XII.

Las superficies de las tres salas principales miden respectivamente: 33.06 (sala fría), 24.41 (sala intermedia) y 29.74 metros cuadrados (sala caliente). Las superficies de las salas intermedia y caliente son muy parecidas a las de las salas correspondientes del baño de Suso ${ }^{11}$ las cuales tienen una superficie de 24 y $33.88 \mathrm{~m}^{2}$. Por otro lado la superficie de la sala fría del baño de Yuso se acerca mucho a la de la misma ${ }^{12}$ en el baño de Yaix, mientras que las superficies de las salas intermedias y calientes presentan variaciones importantes: más de $18 \mathrm{~m}^{2}$ para las salas intermedias de los baños de Yaix y del Pozo Amargo ${ }^{13}$, de 10 a $15 \mathrm{~m}^{2}$ por las salas calientes

10 Baño descrito en esta publicación por Rojas, J. M., 1996, páginas siguientes.

11 La sala fría de este baño no fue excavada por estar bajo un camino. Rojas, J. M., 1996, páginas siguientes.

12 Superficie calculada por el autor a partir de las medidas contenidos dentro del libro de Delgado Valero, C. (1987), 379-386: Baño de Yaix, salas frías: $30 \mathrm{~m}^{2}$, tibia: $43 \mathrm{~m}^{2}$, caliente: $39.30 \mathrm{~m}^{2}$.

13 Las salas intermedia y caliente del baño del Pozo Amargo miden respectivamente 43 y $45 \mathrm{~m}^{2}$ (Passini, J., 1995). 
de los mismos. Se añade que las dimensiones medias de las superficies cubiertas por las salas intermedia y caliente de los baños de San Sebastián de Yuso son muy semejante a las del baño del Caballel ${ }^{14}$, mientras la superficie del espacio ocupado por las tres salas fría, intermedia y caliente se sitúa entre la superficie correspondiente del baño de Yaix y del baño del Angel ${ }^{15}$. Este último baño aparece como el más pequeño de los conocidos hasta este momento en Toledo. Finalmente el baño de San Sebastián de Yuso tiene carácter de un baño público islámico. Además es conforme al modelo de los baños islámicos definido como constituido por una nave a la que se contraponen tres perpendiculares (Delgado Valero, 1987). Sólo se han conservado las tres naves mientras que la sala de acceso ha desaparecido. La iluminación de la sala caliente se conseguía por unos tragaluces de forma de estrella octogonal, confirmando el carácter de un baño de la ciudad (Rivas Rivas, 1982).

Dos alcobas debían existir al extremo norte de la sala caliente, semejantes a las del baño de Suso y al baño del Pozo Amargo (Passini, J., 1995). Dominan en los muros los aparejos de mampostería encintada por una hilada de ladrillo, modo habitual en las construcciones islámicas toledanas (Delgado Valero, C., 1987) de los siglos X a XI. Además las bóvedas de medio cañón están hechas con ladrillo. Estos caracteres subrayan el origen islámico de este baño y una datación a finales del siglo x o durante el XI ¿Hasta cuando siguió utilizándose? A esta pregunta no hay respuesta segura en estos momentos. La única prueba que nos queda de una utilización diferente del baño, está en la puerta de ladrillo (lam. 2) visible sobre el muro externo de la sala del poniente. El arco apuntado de ladrillo se edificó una vez abandonado el uso del fogón y del caldero. Este tipo de arco es poco común anteriormente al siglo XIII. Ello permite establecer que el baño ha podido ser utilizado como tal hasta el final del siglo XII.

Como hemos mencionado en la introducción de la presentación de los baños de Yuso y de Suso es muy difícil encontrar alguna noticia sobre estos dos baños. Formulemos la hipótesis de que el baño de San Sebastián de Yuso puede corresponder al lugar conocido en el siglo XIII por las Bóvedas. En este lugar «el cabildo poseía unas dos casas, cuatro bóvedas, una de

14 Las salas intermedia y caliente, recientemente medidas, tienen una superficie de 22.46 y $28 \mathrm{~m}^{2}$. J. Passini, sin publicar.

15 La superficie del espacio ocupado por las tres salas fría, intermedia y caliente es de 80.3 en el baño del Ángel, $112.3 \mathrm{~m}^{2}$ en el baño de Yaix mientras en el baño bajo de San Sebastián es de 87.21. J. Passini, 1996, sin publicar. 
ellas caída» ${ }^{16}$. Esta bóveda fue reedificada y denominada después bóveda nueva. El cabildo arrendó esta bóveda nueva para hacer pergamino el 28 de enero de $1324^{17}$. Ahora bien, en los libros del refitor desde el siglo XIII al siglo $\mathrm{xv}$, parece que los bienes siguen un orden topográfico ${ }^{18}$, por ejemplo, en la lista de bienes del cabildo de la catedral de Toledo, en $1392{ }^{19}$, se lee «A Cenizar y al baño del arzobispo, al alhandar, a las tenerías, a las bovedas..... De eso se deduce que el lugar de las bóvedas debía encontrarse en torno a las tenerías, lo que constituye un segundo argumento a favor de la identificación del baño de San Sebastián de Yuso con las Bóvedas de los siglos XIV y adelante ${ }^{20}$, sobre todo si tomamos en cuenta que dentro del baño de San Sebastián de Suso se identificaron varias tenerías, aunque no en el baño de Yuso. Así pues, el baño de Yuso estaba por un lado cerca de la Alcurnia, zona activa en la época musulmana, por otro muy cercana de la mezquita de al-Dabbāgīn ${ }^{21}$, es decir de la iglesia de San Sebastián.

El arco apuntado, mencionado en la descripción del estado actual, indica una rehabilitación en los siglos XIII-XIV. Tal rehabilitación facilitó la persistencia del baño mientras que el arruinamiento, en el curso del siglo $\mathrm{xx}$, favoreció la aparición de las subestructuras olvidadas.

\subsection{Conclusión}

Los restos del baño que hasta la fecha se conocía con el nombre de «bovedas» debido al desconocimiento de lo que era, conservan tres naves rectangulares, orientadas de norte a sur, y una nave de dirección oesteeste, cubiertas de bóvedas de medio cañón. Es importante señalar que hasta ahora no se ha identificado ningún arco de caldera en los baños conocidos en Toledo. Revela también la presencia de alcobas y de una pileta, desconocida en los baños toledanos. El estado de conservación de este ba-

16 Izquierdo Benito, R. (1971), 147 y 148, notas 279 y 280, O.F. 929, fol. 30, citado por Delgado Valero, C., 1987, 389, nota 122.

17 Izquierdo Benito, R. (1971), nota 279: A.C.T.E. 8 CI 1.3a citado también por Delgado Valero C (1987).

18 Izquierdo Benito, R. (1971), nota 279, p. 178.

19 A.C.T.E., O.F. 928.

${ }^{20}$ En 1572, en la lista de los bienes del cabildo figura también «Bóvedas» donde tiene "4 bienes: 1 casa, 2 bodegas» (O.F. 1016).

${ }^{21}$ Delgado Valero, C., 1987, 317-321: «La mezquita de al-Dabbagin debió levantarse aproximadamente a finales del siglo x o comienzos del xI en el arrabal de los Curtidores.... a plantear que la iglesia de San Sebastián es sin duda, la mezquita denominada de al-Dabbagin." 
ño permite completar los datos recogidos por los arqueólogos en el baño de Suso. Este baño, como el de Suso, enriquece el conocimiento a la vez de los baños toledanos islámicos y de un área de ocupación humana poco estudiada en el momento, es decir el área al sur de las murallas, sobre la ribera derecha del Tajo.

\section{El baño de San Sebastián de Suso}

El conjunto de estructuras que componen las ruinas que hemos denominado «baño de San Sebastián de Suso», se encuentra sobre una de las zonas altas de la ladera conocida como "rodadero de San Sebastián», a unos 50 metros al suroeste de la iglesia de este mismo nombre.

El descubrimiento de estas ruinas no estuvo motivado por ningún proyecto específico sobre la recuperación de las mismas, sino que se debió a la inclusión de los trabajos de excavación dentro de una campaña de limpieza de las riberas de río Tajo a su paso por Toledo, promovida por el convenio suscrito entre el INEM y el MOPU en $1988{ }^{22}$.

\section{Antecedentes y proceso de excavación}

La primera campaña de excavación se planteó sobre uno de los puntos de la inmensa escombrera que es este rodadero en donde se dejaban ver, apenas, algunos restos de muros y de un arco de medio punto cegado, cuya tipología constructiva nos pareció semejante a la de otros vestigios de Toledo clasificados por distintos autores dentro de la época de dominio islámico de la ciudad. Todos los restos visibles presentaban un aspecto bastante ruinoso, propio del estado de abandono en el que, secularmente, se han visto inmersos éste y otros barrios de la zona sur del casco histórico de Toledo, especialmente los rodaderos que, como veremos más adelante, en las épocas en que estuvieron habitados siempre lo fueron por las clases sociales más bajas.

Gracias a los datos arqueológicos que venimos manejando en los últimos años, podemos confirmar la existencia de abundantes construcciones

22 El interés despertado tras las primeras excavaciones hizo que en 1989 se patrocinara una nueva campaña dentro del mismo convenio, siempre bajo la dirección de J. M. Rojas. 
a lo largo de toda la ladera que, sin duda, debieron formar un barrio habitado durante toda la Edad Media (barrio de las Tenerías) y, sobre todo, en el siglo Xvi, llegando incluso hasta el xx, en el que todavía quedaban pequeños núcleos de casas, en su mayoría en un estado cercano al chabolismo.

Precisamente, estas ruinas fueron uno de los lugares en los que se estuvo dando esa ocupación hasta los años cincuenta, época en la que las autoridades municipales decidieron erradicar algunos de estos núcleos de pobreza, provocando la demolición de varias edificaciones, entre las que se encontraba una de las bóvedas de este baño ${ }^{23}$. Tras su definitivo abandono se completó el proceso de vertido de escombros que se venía produciendo desde hacía siglos, quedando casi completamente sepultadas.

La excavación se planteó desde un principio como una operación de desescombrado, tomando como referencia las estructuras que permanecían a la vista; a medida que iban apareciendo nuevas construcciones las excavaciones se centraban en espacios definidos.

Los rellenos se podrían clasificar en varios tipos, desde los más modernos, cuyos vertidos se produjeron a finales de los años setenta y principios de los ochenta, hasta los más antiguos, originados entre los siglos XI y XIII. Dentro del conjunto de las escombreras recientes se pueden diferenciar dos grandes grupos, por un lado, el de escombros procedentes de demoliciones de edificios, formados por trozos de ladrillo, tejas, algunas piedras y, sobre todo, un alto porcentaje de tierra; por otro lado, están los escombros producidos por desechos domésticos entre los que, fundamentalmente, además de restos de materia orgánica descompuesta, se pueden distinguir bastantes desperdicios de uso cotidiano como envases de plástico, de cristal o ropas, mezclados, en muchos caso con tierras y otros desechos constructivos. Estas escombreras de vertidos recientes ocupan casi todo el conjunto de las ruinas descubiertas hasta ahora, pudiéndose determinar una mayor concentración de los originados por desperdicios domésticos en las zonas comprendidas por lo que sería la sala templada del baño (fig. 8 ; 1) y lo descubierto al este de la misma.

Los rellenos con mayor antigüedad también tiene diferentes orígenes y, por supuesto, distintos momentos de formación. En este sentido

23 Como pudimos comprobar durante el proceso de excavación, correspondiendo a la que posteriormente hemos identificado como sala templada. 


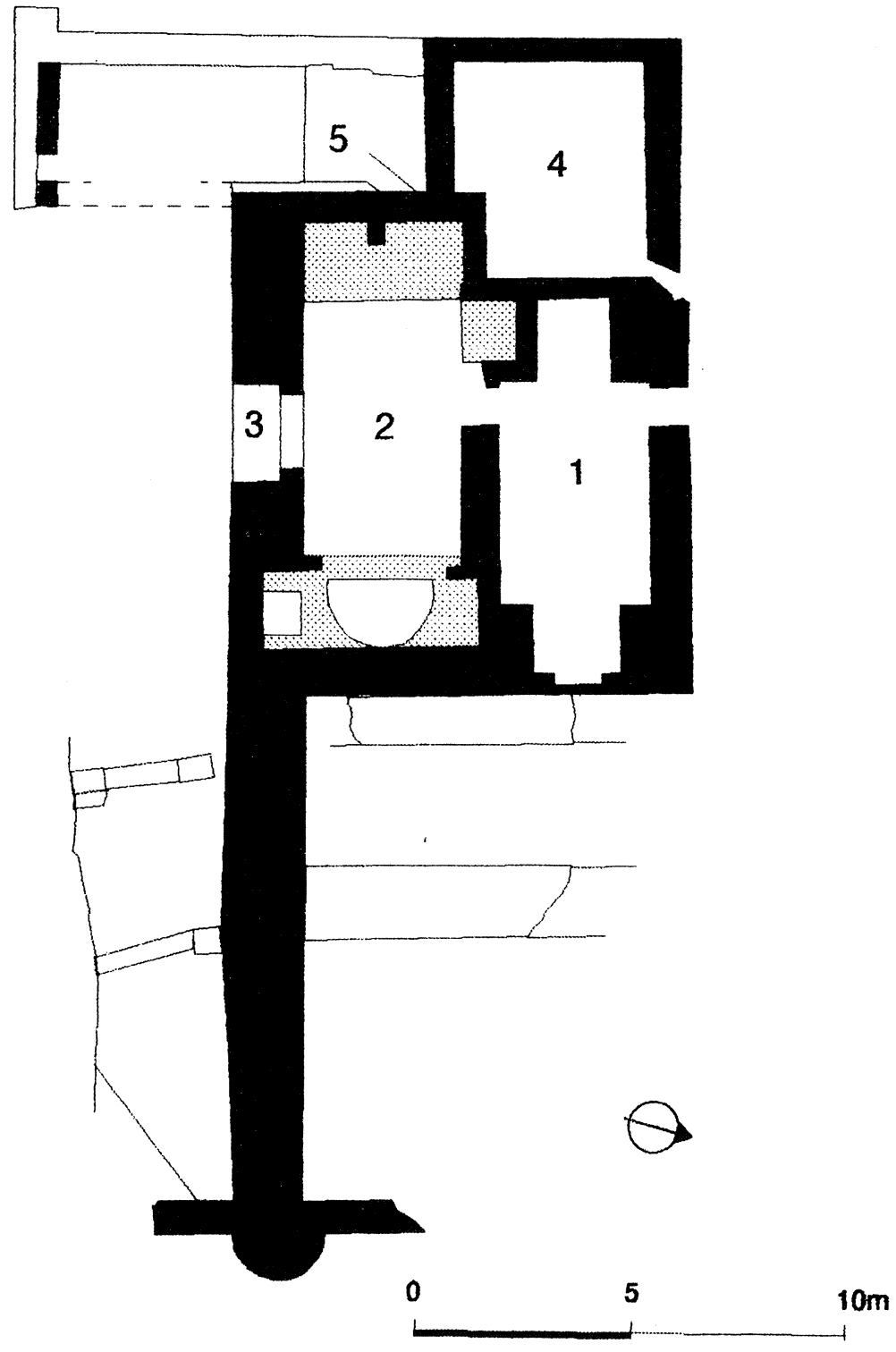

FIGURA 8. Plano general del conjunto excavado: 1. Sala templada; 2. Sala caliente; 3. Sala de caldera; 4. Aljibe; 5 . Alcantarilla; 6 . Prolongación del muro de aterrazamiento del baño; 7. Posible lienzo de muralla. 
podemos encontrar lugares donde el relleno procede exclusivamente de vertidos, como es el caso del extremo más oriental de las ruinas, en el que pueden apreciarse diversos niveles, tanto procedentes de obras de construcción con tierras y esquirlas de recortes de ladrillos, como originados por desechos domésticos, con abudantes restos de ceniza, huesos de fauna, fragmentos de vasijas de cerámicas y otros elementos de uso cotidiano ${ }^{24}$.

El otro tipo de relleno sería el formado a través de la acumulación de tierras o escombros como consecuencia del abandono de determinadas construcciones y, también, por la posterior rehabilitación de estos mismos lugares. Probablemente sea éste el caso más frecuente de la acumulación de rellenos antiguos, tal y como se ha podido comprobar en los espacios correspondientes a las dos salas de los baños (fig. 8; 1 y 2) y la colindante al este de los mismos. Sin duda, la zona más representativa del proceso de abandonos y reagrupaciones llevadas a cabo dentro de estas estructuras a lo largo de la Edad Media y Edad Moderna, sea la documentada en las salas del baño hasta ahora descubiertas.

En estas salas (fig. 8; 1 y 2) se han podido determinar, al menos, tres ocupaciones correspondientes a otras tantas épocas y funcionalidades diferentes. La ocupación más reciente corresponde a un período en el que se utilizaron las dos salas como vivienda, quedando reflejado a través de un suelo de trozos de ladrillos colocados en sardinel descubierto en la mitad oeste de la sala caliente, a unos 0,60 metros por encima del nivel del suelo original y, en la sala templada, a través de un recorte del muro sur de la alcoba (o nicho) del extremo oeste, de un murete fabricado con restos de ladrillos y piedras trabados con barro que tabicaba la alcoba del lado este, y a través de los restos de encalados y revocos que cubrían los paramentos de la alcoba del lado oeste y del muro norte de la sala.

La segunda ocupación registrada correspondería al hallazgo de cinco piletas cuadrangulares, de entre 1,10 y 1,30 m de longitud de sus lados, repartidas entre las dos salas. En la sala caliente se encontraban tres, una entre el ángulo formado por el muro norte y el que separaba el hipocausto de la bañera de la alcoba del lado este y las otras dos, unidas entre sí y adosa-

24 Cabe destacar entre ellos un peine de hueso con púas en dos de sus lados y una figurita de barro representando a un jinete, actualmente en curso de estudio para una publicación sobre juguetes medievales. 
das al muro sur, entre la pila de la alcoba y el ángulo suroeste y el centro del arco de la boca del hipocausto. En la sala templada se hallaba una pila cerı ndo el acceso entre ambas estancias y la otra adosada al ángulo noreste de la sala. Como características comunes a todas las pilas, encontramos que se fabricaron excavando el relleno de tierra-escombrera preexistente y empleando ladrillos y piedras con buena argamasa para las paredes y suelos. Tenían una piedra de granito con forma cilíndrica (de unos 0,40 $\mathrm{m}$ de diámetro) clavada en el centro (aunque en una había sido robada y en otra desplazada) y se encontraban a un mismo nivel, si bien las de la sala caliente, que estaban unos centímetros más bajas que las de la templada, tenían los bordes a una altura ligeramente por debajo de lo que suponemos que sería el nivel del suelo original de este baño. A este período, cuya ocupación estaría estrechamente vinculada a un uso del recinto como tenería, también pertenecerían varios canalillos o chorreros de desagüe, fabricados con los mismos materiales que las piletas; el tramo conservado de mayor longitud partía de la sala templada en sentido suroeste-noreste y, tras dar un giro hacia el sur, cruzaba bajo el muro que separaba esta sala y la alcoba de la pila del extremo este de la sala caliente, cruzándola de norte a sur, al que desembocaba un resto de tramo proveniente de esta sala 25 .

El período más antiguo corresponde a la construcción y utilización del edificio del baño, en donde, como veremos más adelante, se han podido detectar, al menos, dos fases. Evidentemente las estructuras originales han sufrido grandes transformaciones a lo largo de los siglos, siempre dentro de un proceso de evolución hacia el deterioro, favorecido por los expolios, las demoliciones para adaptarlas a nuevas funciones o por el ataque de los agentes atmosféricos. Los únicos restos no arquitectónicos asociados al período de utilización de los baños, han sido los del estrato de cenizas (de entre 0,30 y $0,40 \mathrm{~m}$ de espesor) que permanecía acumulado sobre el suelo del hipocausto.

\section{Descripción del conjunto de las estructuras}

En este apartado vamos a seguir un orden cronológico, de acuerdo con el cual empezaremos describiendo las estructuras más antiguas que, a

25 Otro pequeño tramo de chorrero se conserva sobre el muro que hay adosado al paramento de la fachada del lado este, que parece haber estado asociado a una pila de tenería cuyos restos todavía se conservan en esta zona bajo dos capas de baldosas relacionadas con la época de hábitat de estas estructuras. 

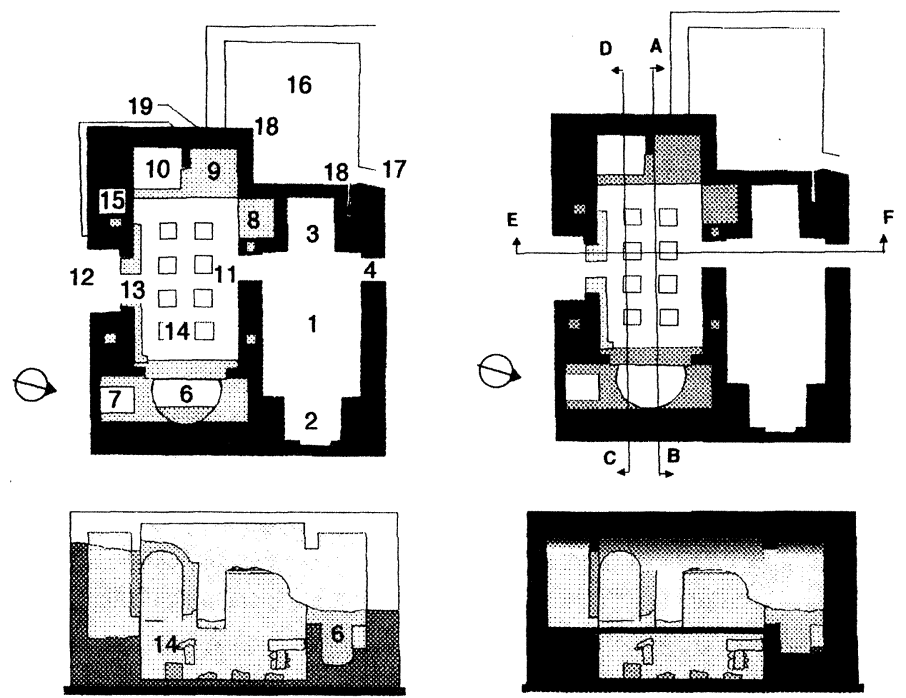

Sección A-B
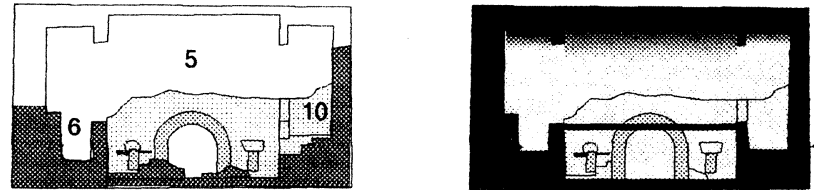

Sección C-D

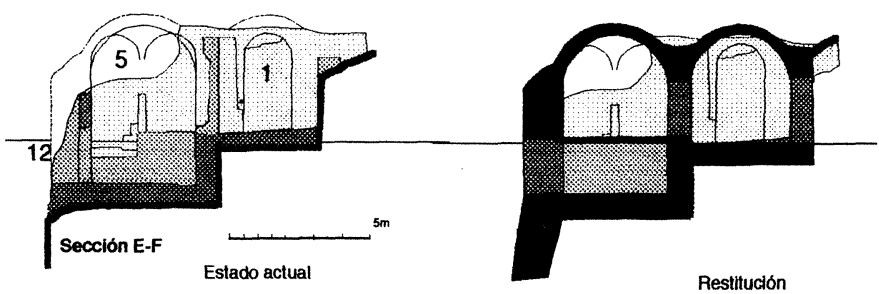

Figura 9. Plano y secciones del baño de San Sebastián de Suso: 1. Nave central de la sala templada; 2 . Alcoba del extremo noreste de la sala templada; 3 . Alcoba del extremo suroeste de la sala templada; 4 . Puerta de acceso desde la sala fría a la sala templada; 5 . Nave central de la sala caliente; 6 . Alcoba de la pila del extremo noreste de la sala caliente; 7 . Posible alcoba de la sala caliente; 8 . Alcoba junto al ángulo oeste de la sala caliente; 9 . Alcoba geminada con pila en el extremo suroeste de la sala caliente; 10 . Alcoba geminada con pila en el extremo suroeste de la sala caliente; 11 . Hipocausto bajo la nave central de la sala caliente; 12. Sala caldera; 13. Revestimiento de ladrillos refractarios en las paredes del hipocausto; 14. Pilares de sustentación del suelo de la sala caliente; 15 . Toberas y chimeneas del hipocausto; 16. Depósito del aljibe; 17. Acceso del canal de abastecimiento; 18. Canalillos de distribución del agua en las salas; 19 . Alcantarilla. 
su vez, constituyen el núcleo básico de este conjunto arquitectónico pasando a describir, posteriormente, el resto de edificaciones que se han ido articulando alrededor de ellas en sucesivas etapas históricas.

La habitación más septentrional de las hasta ahora descubiertas correspondería a la sala templada cuya planta presenta una forma rectangular orientada noreste-suroeste en su eje máximo y sus medidas son de 5,20 por $3,50 \mathrm{~m}$ en el lado suroeste y $3,57 \mathrm{~m}$ en el noreste (fig. $9 ; 1$ ). En el centro de estos dos lados menores se abren dos alcobas, la del noreste (fig. 9; 2) de $2,05 \mathrm{~m}$ de ancho por 1,60 de fondo, presentando un pequeño entrante de 0,17 por $1,10 \mathrm{~m}$ en la pared opuesta al lado abierto; la alcoba del extremo suroeste (fig. $9 ; 3$ ) tiene unas medidas de 1,75 de ancho por $1,86 \mathrm{~m}$ de fondo. También presenta dos puertas abiertas junto al extremo suroeste de los muros noroeste y sureste de la sala, ambas se hallan orientadas en el mismo eje y la anchura, en ambos casos, es de $0,95 \mathrm{~m}$. La puerta del muro noroeste (fig. 9; 4) se encuentra tabicada con piedras y barro y comunicaría con la sala fría, en tanto que la del muro sureste daba acceso a la sala caliente. La altura real de los muros sólo se conserva en la alcoba del extremo suroeste con 3,10 m, existiendo también parte del arranque de la bovedita de ladrillo que cubría este cubículo. En cuanto a la fábrica diremos que está construida con un aparejo formado por hiladas simples de mampuestos irregulares entre verdugadas simples de ladrillo que recorren todo el paramento hasta unirse con los machones de ladrillo que se hallan siempre en rincones, esquinas y/o jambas, trabado con argamasa (fig. 11).

Un detalle a tener en cuenta son los rebajes verticales tallados con forma de media caña que hay en los machones de ladrillo que flanquean los accesos a las dos alcobas.

En la alcoba del extremo suroeste se aprecia que la edificación se levanta directamente desde la roca madre, mientras que en la alcoba opuesta los muros se asientan sobre una plataforma de piedras y tierra apisonada que nivela la fuerte pendiente que tiene el terreno en esta zona. El suelo original tampoco se conserva, si bien creemos que arrancaría a partir de una pequeña zarpa o resalto que puede distinguirse en la base del paramento del muro sureste.

La sala caliente (fig. 8; 2), también orientada noreste-sureste en su eje máximo, se halla al sureste de la templada, separada de ésta por un muro de $0,82 \mathrm{~m}$. Su planta es, sin duda, la más compleja, ya que presenta, además de una nave central rectangular $(5,91$ por $3,68 \mathrm{~m})$ otras cinco alcobas dispuestas en los extremos noreste y sureste. La alcoba del extremo nores- 
$A Q$, xVIII, 1997

te (fig. 9; 6) es de planta rectangular $(3,67$ por 1,60 m) orientada noroestesureste en su eje más largo. Centrada respecto al lado noreste de la nave central existe, en esta alcoba, una pila con planta de tres cuartos de circunferencia fabricada con mampostería ordinaria sin ningún tipo de enlucido especial en sus paramentos, tan sólo conserva una fina capa de concreciones calcáreas producida por el uso de la misma como contenedor de agua. El cimiento del suelo de la pila (cuyo espesor es de $0,55 \mathrm{~m}$ ) estaba fabricado, a la vez que la pared que separaba ésta del hipocausto, mediante una fábrica basada en piedras irregulares de tamaño medio y pequeño trabadas mediante abundante argamasa especial que les da gran dureza. El suelo, del que sólo se conservan unos trozos, era de losetas de cuarcita rosácea. En la zona opuesta al muro que la separaba del hipocausto se rellenó, en una remodelación posterior, un espacio con forma de segmento de círculo fabricado con ladrillo y argamasa. La profundidad desde la superficie conservada en la actualidad hasta el suelo de losetas es de 0,84 m. En el lado noroeste de esta alcoba se conserva la base de una mocheta de ladrillo que, supuestamente, formaba parte de un arco que encuadraba el acceso desde la nave central.

A unos $0,50 \mathrm{~m}$ al sureste de la pila, a través de un escalón de ladrillo con restos de enlucido pintado de rojo, se insinúa el acceso a otra pequeña alcoba que debió existir dentro de un espacio abierto en el grueso muro de contención $(1,62 \mathrm{~m})$ que sustenta la mayor parte de las estructuras del baño (fig. 9; 7). Debido al alto grado de ruina existente en el extremo noreste de la sala caliente son muy pocos los datos que podemos aportar sobre sus muros y bóvedas, aunque creemos que la bóveda de la alcoba de la pila tenía sus arranques en las paredes de los lados noreste y suroeste.

Junto al ángulo noroeste de esta sala se encuentra la otra alcoba (fig. 9; 8) que se sale del rectángulo que forman la nave central y las otras alcobas que hay en sus extremos. Tiene una planta ligeramente rectangular y su bóveda (la única conservada en este baño) es de medio cañón cuyos hombros se asientan sobre los muros noreste y suroeste. No conserva ningún resto de suelo ni de la jamba que sirviera de apoyo al supuesto arco que flanquearía el acceso. Es de destacar la presencia de un pequeño hueco cuadrangular fabricado originalmente en la pared noroeste que comunica con la alcoba suroeste de la sala templada.

En el extremo suroeste de la sala caliente existen dos alcobas separadas por un resto de tabique de ladrillo de $0,29 \mathrm{~m}$ de espesor. La alcoba que coincide con el ángulo noroeste (fig. 9; 9) conserva parte del arranque 
de una bóveda de medio cañón que se apoya en el muro noroeste, el cual también conserva una jamba de ladrillo con rebaje vertical con forma de media caña; sobre esta jamba hay una piedra caliza, a modo de salmer, en la que se apoyan los restos de un posible arco de ladrillo.

En la alcoba del ángulo suroeste (fig. 9; 10) encontramos, como característica principal, la presencia de un cimiento de piedras y argamasa similar al de la pila del extremo noreste que, asentándose sobre una bancada de mampostería ordinaria, contactaba con la pared del hipocausto. Sobre esta cimentación aparece un posible suelo original formado por losetas de piedra cuarcítica similares a las de la otra pila, aunque encima de ellas también tiene tres capas de ladrillos trabados con argamasa pertenecientes a reestructuraciones posteriores. Junto al tabique que la separa de la otra alcoba hay un escalón o poyete de ladrillo que todavía conserva escasos restos de concreciones calcáreas bajo una fina capa de enlucido de cal pintada de rojo. En el paramento del muro sureste resalta una supuesta jamba de ladrillo con rebaje de media caña, similar al de la alcoba noroeste.

Ocupando el mismo espacio que la sala central se halla, bajo ésta, el recinto del hipocausto (fig. 9; 11), al que se le unía la pequeña sala de caldera abierta en la zona central del muro sureste (fig. 9; 12); ambas se comunicaban a través de un arco de medio punto fabricado con ladrillo de $1,90 \mathrm{~m}$ de alto por 1,71 $\mathrm{m}$ de ancho. Desde las dos jambas aparecen restos de un revestimiento de ladrillos que recorre parte del paramento interior del muro sureste (fig. 9; 13) e inicia el del noreste; se trata de ladrillos refractarios colocados a tizón trabados entre sí y unidos a los paramentos mediante barro, también refractario. Otros importantes elementos de hipocausto son los ocho pilares de planta cuadrangular fabricados en ladrillo y barro refractario que se hallaban dispuestos en dos filas de a cuatro paralelas entre sí y a los muros sureste y noroeste (fig. 9; 14). Los pilares se asientan sobre la roca madre (zona noroeste) y sobre la plataforma artificial de cimentación fabricada con piedras y tierra (zona sureste y este), guardando la misma distancia $(0,60 \mathrm{~m})$ entre sí y respecto al murete de revestimiento de los paramentos. En ambos casos, las superficies conservan importantes restos de costras formadas al fundirse el barro por las altas temperaturas. Las toberas o chimeneas (fig. 9; 15), cuyos huecos se abren a pocos centímetros del suelo (entre 0,28 y $0,61 \mathrm{~m}$ ) y se sitúan, dos en el muro sureste, a ambos lados del arco, y otros dos en el muro noroeste, más o menos frente a los otros dos; el siguiente tramo consiste en un hueco vertical de sección cuadrangular que recorre el centro de esos muros hasta, supuestamente, su salida por encima de la bóveda. 


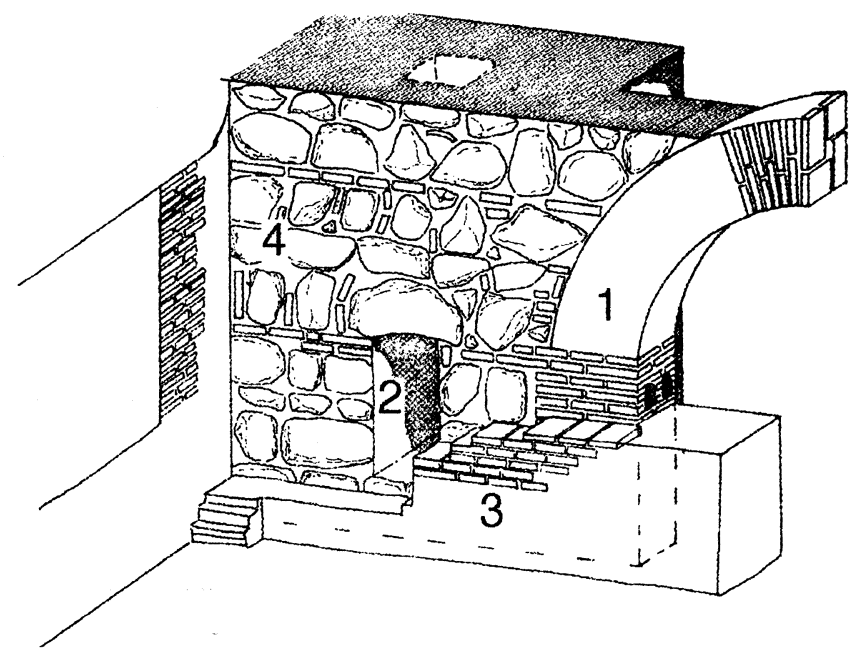

Figura 10. Baño de San Sebastián de Suso: detalles: 1. Boca de la caldera; 2. Tobera; 3. Muro de ladrillo refractario; 4. Aparejo del hipocausto.

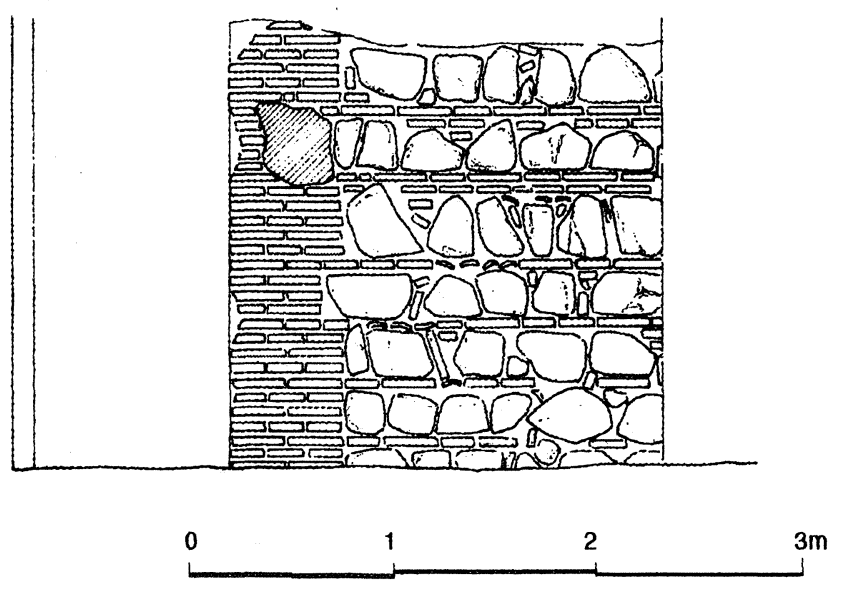

Figura 11. Baño de San Sebastián de Suso: detalle del aparejo de la sala templada. 
Otra parte imprescindible en unos baños es el aljibe o depósito, en el que se recogía el agua y desde el que se distribuía a las salas. En el caso de estos baños se ubica tras el ángulo formado por las uniones de los extremos occidentales de las salas caliente y templada (fig. 9; 16). Dado que sólo ha sido excavado en un pequeño porcentaje, apenas conocemos sus características. Podemos decir que tiene una planta con forma casi cuadrada y sus muros presentan un espesor de entre 0,48 y $0,65 \mathrm{~m}$. En la zona excavada pudimos descubrir que el canal que le aporta el agua se halla en la parte superior del ángulo norte orientado en esta dirección, cubierto con falsa bóveda de aproximación de hiladas de ladrillo y enlucido rojo en sus paramentos (fig. 9; 17). En las paredes del aljibe también se distinguen dos capas de enlucido con distinta tonalidad de pintura roja. Sobre los muros que dividen el aljibe de las salas templada y caliente se conservan algunos restos de posibles canalillos de sección rectangular; quizá el mejor conservado sea el que recorre longitudinalmente la coronación del muro suroeste de la sala caliente (fig. 9; 18).

En la base del ángulo formado por el muro sureste del aljibe y el suroeste de la sala caliente aparece una alcantarilla fabricada con paredes de hiladas horizontales de mampostería ordinaria separadas por verdugadas de ladrillo y cubierta arquitrabada con losas graníticas (fig. 9; 19). El escaso tramo que se mantiene visible bajo las salas calientes y templada, está orientado hacia el norte, cambiando el rumbo hacia el suroeste y discurriendo varios metros adosados a la base del muro suroeste de la sala caliente donde desemboca un pequeño conducto que parece venir de la base de la alcoba de la pila suroeste de la sala caliente.

Entre otras estructuras de las hasta ahora descubiertas que pudieran estar asociadas a las de los baños, contamos con un posible muro de contención adosado al muro noreste de las salas templada y caliente (fig. 8), la prolongación, hacia el noreste, del muro sureste de la sala caliente (fig. 8, 6) y su entronque con el muro que baja de noroeste a sureste (fig. $8 ; 7$ ). Todos ellos tienen el mismo tipo de aparejo al igual que el del resto de las edificaciones del baño, es decir, hiladas simples de mampuestos irregulares separadas también por verdugadas simples de ladrillo que traban con machones de ladrillo sólo en las esquinas y jambas. En este sentido debemos hacer una excepción en el paramento exterior del muro sureste de la sala caliente y su prolongación, ya que, en vez de verdugadas de ladrillo, se han empleado pequeñas lajas de piedra; es posible que esto se deba a su condición de gran muro de contención que, aun teniendo en 
cuenta su espesor $(1,60 \mathrm{~m})$ presenta una clara inclinación en el sentido de la vertiente del rodadero (sureste).

Los demás muros que se encuentran, en su mayoría, adosados o sobre las paredes del baño están construidos con aparejos de mampostería ordinaria trabada con barro, conservando, en algunos casos, revocos de argamasa o yeso y corresponden a viviendas de épocas posteriores a la del baño.

\section{Interpretación arqueológica: Reconstrucción hipotética del baño}

Atendiendo a las funciones socio-religiosas que desempeña el "hammām» en el mundo islámico parece claro que deben emplazarse en barrios concurridos e incluso junto a mezquitas, con fácil acceso al abastecimiento de agua. En el caso del baño aquí descrito, parece hallarse en lo que, durante la Edad Media, fue el barrio de las Tenerías o de los Curtidores (al-Dabbägin), densamente poblado por clases sociales bajas con, al menos, una mezquita en sus proximidades (en la actual iglesia de San Sebastián) ${ }^{26}$.

Creemos que el condicionante de más peso que justifica la construcción del baño en esta zona, es la proximidad y fácil acceso a una corriente de agua; nos referimos a la vaguada natural con origen en la zona del convento de San Pedro Mártir que desciende por la actual calle de Santa Ursula hasta alcanzar la zona de la iglesia de San Sebastián ${ }^{27}$, lugar en el que se produciría la correspondiente captación y desvío del caudal hacia estos baños.

Indudablemente debieron existir razones de mucho peso a la hora de elegir un lugar tan abrupto para la edificación del baño, ya que esta circunstancia obligó a realizar un mayor esfuerzo constructivo, basando la cimentación en el levantamiento de un largo y grueso muro de contención paralelo a las curvas de nivel (fig. 8; 6). Tras este muro se rellenaron, con piedras y tierra, los lugares más deprimidos, a la vez que se recortaron los afloramientos rocosos, resultando de esta manera una especie de bancal o

26 Delgado Valero, C. (1987). Toledo islámico: ciudad, arte e historia. Toledo, 317-321.

${ }^{27}$ Visible en el plano topográfico de Toledo de Rey Pastor (Toledo, 1927), que figura como número 1 de los publicados por J. Porres (Porres, J. 1989: Planos de Toledo. IPIET, Toledo, 1989). 
terraza sobre cuya plataforma se levantaron las estructuras de la sala caliente junto con el muro que la separaba de la sala templada que, a su vez, serviría de muro de contención para realizar un nuevo aterrazamiento a un nivel superior, sobre el que se construyeron los muros de esta sala y, quizá, los de la fría.

Suponiendo que en este baño existieran las salas y estructuras imprescindibles en los años islámicos, creemos que la sala del agua fría se encontraba tras la puerta tabicada en el muro noreste de la sala templada, con unas dimensiones y características similares a las de esta última. También es probable que el acceso a la sala fría se hiciera desde una sala de estar o vestuario (bayt al-mušallah), próxima a la entrada desde la calle. $\mathrm{Al}$ no estar completamente excavado el baño nos es casi imposible poder precisar la ubicación de esta sala, si bien no descartamos que pudiera hallarse tras el muro noreste de las salas templadas y caliente (fig. 8).

Es bastante probable que el acceso al edificio se hiciera desde alguna pequeña callejuela situada al norte del mismo, orientada hacia la actual iglesia de San Sebastián.

En cuanto al sistema de calefacción del baño de San Sebastián de Suso, parece bastante clara la existencia de una pequeña sala bovedada tras el muro sureste del hipocausto (sala de caldera) que conectaba con éste a través de un arco de medio punto fabricado enteramente con ladrillo. El hipocausto se hallaba, únicamente, bajo la nave central de la sala caliente, separada de esta mediante un piso fabricado con varias capas de ladrillo y barro refractarios que sería sustentado por los ocho pilares cuadrangulares y por la pared de revestimiento que recorría los paramentos del hipocausto formando entre todos ellos un sistema de falsas bóvedas por aproximación de hiladas de ladrillos ${ }^{28}$, al igual que encontramos en el canal de aprovisionamiento del aljibe. El piso iba adosado a las paredes de la sala caliente en las que se aprecian algunas rozaduras de acoplamiento que nos indican la posición real del suelo.

La pared de ladrillos y barro refractario que recubría los paramentos del hipocausto es muy probable que continúe dentro de la sala de caldera, a pesar de no haberse conservado ningún resto de este tipo. La función de esta pared de revestimiento era, fundamentalmente, evitar que las altas temperaturas del hipocausto provocaran agrietamientos en los muros del edificio, fabricados con materiales más rígidos (piedras graníticas y arga-

28 Pavón Maldonado, B. (1990). Tratado de Arquitectura Hispanomusulmana. I. Agua. Consejo Superior de Investigaciones Científicas. Madrid, 344-345. 
masa), además de aportar parte del soporte del suelo de la nave central de la sala caliente.

Las cuatro toberas, abiertas junto a los rincones de hipocausto, facilitaban la distribución del calor producido por la quema de combustible junto a la boca que unía este recinto con la sala de caldera, al tiempo que las dos que subían por el muro noroeste, aportaban calorías a la sala templada.

Otra importante función del hipocausto era la de calentar el agua de las pilas situadas en las alcobas de los extremos noreste (fig. 9; 6) y suroeste (fig. $9 ; 10$ ), cuyos cimientos, fabricados con argamasa de características hidráulicas, estaban en contacto con las paredes de ladrillo refractario del hipocausto. Así, en el caso de la pila de la alcoba del lado noreste, al tener más volumen de agua para calentar, también era mayor la superficie del cimiento y pared que entraba en contacto con el hipocausto. Precisamente, este interés por el calentamiento del agua hace que en una de las reformas del edificio se rellene con fábrica de ladrillo y argamasa el tercio noreste de la pila, de manera que al disminuir el volumen del agua contenido, éste puede calentarse antes e, incluso, alcanzar una mayor temperatura.

Parece incuestionable que la sala caliente fuera la más compleja y la de mayor importancia dentro del baño, prueba de ello es que, además del sistema del hipocausto, tenía dos alcobas destinadas a contener pilas con agua caliente y otras tres en las que, con cierta intimidad, se efectuarían las abluciones de las zonas sexuales. Los bordes de las dos pilas estarían al nivel del suelo de la sala, con un posible escalón de acceso al interior de la pila de la alcoba noreste, mientras que en el suroeste existe un poyete, supuestamente, para sentarse en el interior más que para acceder a ella. Tenemos muy pocos datos que nos permitan conocer cómo eran los suelos, puesto que tan sólo contamos con los restos de suelo documentados en las dos pilas; es muy probable que, en un principio, las pilas y las alcobas tuvieran losetas de cuarcita que, en reformas posteriores, serían sustituidas por baldosas de barro cocido.

De la sala templada podemos decir que tendría el suelo al mismo nivel que el de la sala caliente y que las alcobas que tiene en los extremos noreste y suroeste (fig. 9; 2 y 3 ) debieron tener en su acceso sendos arcos de herradura apoyados sobre salmeres de piedra caliza y sobre pequeñas columnas con fuste cilíndrico, similares a los geminados que existirían en las alcobas del extremo suroeste y en el acceso al noreste de la sala caliente, aunque este último de mayores dimensiones que los demás.

Parece bastante lógico suponer que las paredes y bóvedas irían enluci- 
das con revocos de cal pintados, en gran parte, de color rojo tal y como se han conservado en otros baños medievales de la Península ${ }^{29}$, si bien en el de San Sebastián de Suso tan sólo contamos con pequeños restos de enlucido en dos de las alcobas de la sala caliente (fig. 9; 7 y 10).

El abastecimiento de agua que, como hemos dicho al principio de este apartado, constituye uno de los principales condicionantes a la hora de ubicar unos baños, se realizaba mediante un canal subterráneo que, supuestamente, captaba las aguas de la vaguada que pasa junto a la iglesia de San Sebastián y que en la actualidad bordea las ruinas del baño de Yuso. La distribución desde el aljibe hasta las salas se hacía mediante canalillos fabricados sobre los muros; tal vez el más importante fuera el que discurre a lo largo del muro del extremo suroeste de la sala caliente, que abastecería, fundamentalmente, a la sala de las calderas.

La alcantarilla (fig. 9; 19) se debió construir al mismo tiempo que la fundación del baño de Suso, pero parece evidente que, por sus dimensiones, ésta recogiera las aguas de toda la barriada existente al norte de San Sebastián y que su paso bajo los baños fuera aprovechado para verter las aguas sucias. Uno de estos vertidos se hacía desde la pila situada en el rincón suroeste de la sala caliente (fig. 9;10) a través de un pequeño canalillo abierto en los cimientos del muro, aunque sería cegado durante alguna de las reformas que se hicieran en los baños. La orientación norte-sur de la alcantarilla, al igual que la del canal de traída de aguas al aljibe, pudiera ser un buen indicador de la posible ubicación de la puerta de «Los Curtidores" (bāb al-Dabbāginn") y del camino que comunicaba San Sebastián con el baño de Suso y el barrio de Las Tenerías.

Las reformas habidas en este edificio durante el período de utilización como baño parece que estuvieron relacionadas, principalmente, con los lugares destinados a contener agua, tal y como podemos comprobar en el aljibe donde existen dos capas de enlucido de los paramentos interiores, en la pila del extremo noreste de la sala caliente que fue rellenada parcialmente con una pared de ladrillos y en la pila del rincón sur de la misma sala, en donde además de poner un enlucido pintado de rojo, se recreció el suelo con tres capas de ladrillos y argamasa sobre las losetas de piedra originales.

Las mayores modificaciones del edificio con posterioridad a los baños son las llevadas a cabo para su transformación en tenería, construyéndose

${ }^{29}$ Pavón Maldonado, B. (1990), op. cit., 350-355. 
diversas piletas para curtido y canalillos de desagüe que rompieron varios muros.

\section{Discusión}

Aunque hasta el momento carecemos de datos, tanto de fuentes escritas como arqueológicas que nos aporten fechas concretas sobre la fundación del baño de Suso, no obstante sí podemos ofrecer una serie de razonamientos que ayuden a dar un encuadre histórico con sus correspondientes cronologías relativas.

En los últimos estudios realizados sobre el conjunto de los baños conocidos hasta ese momento en la ciudad de Toledo ${ }^{30}$ se han dado fechas para las fundaciones en torno a los siglos x y XI, basándose en que tras la entrada de Alfonso VI no se tiene noticia de que se construya ningún baño $\mathrm{y}$, sobre todo, en el tipo de aparejo empleado en la construcción de los mismos ${ }^{31}$. También el tipo de aparejo es uno de los principales argumentos de J. Passini para fechar como islámicos los baños del Pozo Amargo ${ }^{32}$. En cualquiera de estos casos, el tipo de aparejo es el mismo que el empleado en la construcción de los muros de los dos edificios de baños de San Sebastián, es decir, son aparejos formados por hiladas simples de mampuestos irregulares entre verdugadas, también simples, de ladrillos colocados a tizón (figs. 10 y 11). El hecho de que la mezquita del Cristo de La Luz ( $b a \bar{b}$ al-Mardūm) esté edificada con este mismo tipo de aparejo y que se conozca que su fecha de fundación o reconstrucción es de finales del siglo $\mathrm{x}$, ha supuesto que se tome como punto de referencia para fechar construcciones con elementos similares ${ }^{33}$. Tanto el descubrimiento en 1991 de una lápida con caracteres cúficos empotrada en un muro con este tipo de aparejo de la fachada de la iglesia de Santa Justa y Rufina, en el que se halla un arco de herradura fechado en época califal ${ }^{34}$, como el hallazgo que realizamos durante una intervención arqueológica, a principios

30 Delgado Valero, C. (1987), op. cit., 356-418.

31 Delgado Valero, C. (1987), op. cit., 386-405.

32 Passini, J. (1995): "Le bain du Pozo Amargo (Tolède)». Archéologie Islamique, 5, 45.

${ }_{33}$ Delgado Valero, C. (1987), op. cit.

34 Paz Escribano, M. de, y Juan García, A. de (1996): "Iglesia de Santa Justa y Rufina». Toledo; Arqueología en la ciudad. Patrimonio Histórico-Arqueología 13. Servicio de Publicaciones de la Junta de Comunidades de Castilla-La Mancha. 
de 1996, en un solar de la calle del Potro ${ }^{35}$, junto a la iglesia de Santiago del Arrabal, en el que aparecieron gran número de cerámicas de tipología califal/taifa dentro de un relleno que cubría varios muros con aparejos similares a los de la mezquita del Cristo de la Luz, creemos que vienen a reforzar la hipótesis de que el aparejo de hiladas simples de mampostería entre verdugadas, también simples, de ladrillo, sería el empleado en la mayor parte de las construcciones de Toledo durante los siglos X, xI y, posiblemente, XII. Razón por la que también concedemos a los baños de San Sebastián de Suso y de Yuso una cronología que estaría entre los siglos x y XI.

La inclusión de estos baños dentro de una tipología nos parece, hoy por hoy, un tanto precipitada y, sobre todo, si a través de ella pretendemos llegar a establecer cronologías. En este sentido, atendiendo a la disposición de las salas de los baños de Toledo observamos que a pesar de las lógicas similitudes existentes entre ellos, no hay ninguno igual. Entre los dos de San Sebastián parece bastante clara su similitud en aspectos como la ubicación, el tipo de aparejo y la sala caliente ${ }^{36}$, si bien no sucede lo mismo con la tipología de la sala templada y su acceso desde la sala fría que, en el baño de Yuso, se hace a modo de codo a través de una pequeña sala con alcoba (fig. 7), mientras en el de Suso el acceso de una sala a otra es directo con las puertas en un mismo eje (fig. 9). Es probable que además de la influencia de las tipologías heredadas de la antigüedad y de las necesidades que imponga el lugar en que se construya el baño ${ }^{37}$ existan otras razones que expliquen las diferencias tipológicas entre baños de una misma ciudad con lugares de ubicación y cronologías parecidas.

En los baños públicos conocidos hasta ahora en la ciudad de Toledo podemos establecer una serie de características comunes como son: la disposición en paralelo de las tres salas principales del baño (sala fría, templada y caliente) cuyas plantas son, más o menos, rectangulares y un sistema de bóvedas de medio cañón en todas ellas.

Las características vistas hasta ahora unidas a los datos cronológicos con que contamos en los baños toledanos, nos hacen disentir de la clasifi-

35 Excavación arqueológica contractual desarrollada por la empresa Arqueología y Patrimonio, S. L., en la finca correspondiente al núm. 11 de esta calle, dirigida por J. M. Rojas y R. Villa.

36 V. J. Passini, supra.

37 Pavón Maldonado, B. (1990), op. cit., 305-307. 
cación y cronología ofrecida por R. Azuar ${ }^{38}$ pues consideramos que, independientemente de que los baños con "tres salas y el horno y dispuestas en paralelo, casi sin distinción de tamaño entre estas salas .../... con bóvedas de medio cañón" se hubieran seguido construyendo en fechas posteriores al siglo XIII, sin duda se trata de una de las tipologías con mayor antigüedad en el mundo islámico peninsular. A este mismo tipo de baños pertenecerían el del Salón Rico de Madīnat al-Zahrā' y el de construcción más humilde de Vascos (Navalmoralejo, Toledo) fechados, igualmente, en el siglo $\mathrm{x}^{39}$.

La ubicación de los baños de San Sebastián muestra una clara relación con la vaguada natural sobre la que se encuentra la actual calle de Santa Úrsula en la que, al igual que en las otras vaguadas importantes de la ciudad, se dan manantiales naturales ${ }^{40}$.

Esta relación baños-vaguadas naturales nos explica la concentración de los baños de Pozo Amargo ${ }^{41}$, de Yaix, del Caballel ${ }^{42}$ y del Cenizal ${ }^{43}$, emplazados en una pequeña zona comprendida entre las vaguadas de las calles del Pozo Amargo y del Barco.

Aceptando la relación de proximidad entre baños y mezquitas y, aun considerando la hipótesis de que la actual iglesia de San Sebastián hubiera sido una mezquita ${ }^{44}$, la necesidad imperiosa de encontrar un lugar apropiado obliga a la instalación de los baños de Suso y Yuso fuera del recinto amurallado con bastante proximidad entre ellos y dentro de un barrio poco extenso.

Localizaciones de baños en circunstancias parecidas a los de San Sebastián se dan en las agrestes ciudades medievales de Ronda ${ }^{45}$ y Vascos 46 en las que el «hammām» se halla fuera de las murallas y dentro de sus res-

38 Azuar Ruiz, R. (1989): «El hammam musulmán en al-Andalus». Baños árabes en el País Valenciano. Alicante, 38 y 39.

39 Izquierdo Benito, R. (1986): "Los baños árabes de Vascos (Navalmoralejo, Toledo)". Noticiario Arqueológico Hispánico, 28, 242.

40 La vaguada de mayor entidad es la formada por las actuales calles de la Bajada al Colegio de Infantes y del Barco en la que, a su vez, confluyen las vaguadas de la calle Tornerías y de Nuncio Viejo (esta última cruzando bajo la catedral).

41 Passini, J. (1995), op. cit., 35.

42 Delgado Valero, C. (1987), op. cit., 370-386.

43 Passini, J., y Molénat, J. P. (1995): Toledo a finales de la Edad Media. I. El barrio de los Canónigos. Colegio Oficial de Arquitectos de Castilla-La Mancha. Delegación de Toledo. Toledo, 127 y 132.

44 Delgado Valero, C. (1987), op. cit., 317-321.

45 Torres Balbás, L. (1982). "La acrópolis musulmana de Ronda». Crónica de la España musulmana, 2, 400-404.

46 Izquierdo Benito, R. (1986), op. cit., 195. 
pectivos barrios de tenerías, aunque con una diferencia sustancial entre éstos y los de Toledo, pues, mientras en Ronda y Vascos las captaciones se hacían, respectivamente, desde el río Guadalevín y arroyo de la Mora, en los de Toledo se abastecían desde manantiales y/o pozos abiertos en las capas freáticas. Estas circunstancias suponen un importante condicionante en este tipo de ciudades en las que provoca la ausencia de esta clase de establecimientos en otros barrios populosos, al contrario que en poblaciones con fácil acceso a las capas freáticas como Valencia ${ }^{47}$ en donde la localización por los barrios de la ciudad es más homogénea.

Al igual que sucede en los orígenes del baño de San Sebastián de Suso, también carecemos de datos arqueológicos y de las fechas aproximadas en las que dejó de usarse como tal. Las únicas referencias sobre un baño en el barrio de San Sebastián las conocemos a través de un documento mozárabe del siglo XIII ${ }^{48}$ que cita un edificio ya en ruinas situado dentro de la ciudad. Este dato sobre el emplazamiento del baño nos hace descartar que se trate de ninguno de los dos descritos en este artículo pues ambos se hallan fuera del recinto amurallado ${ }^{49}$.

El uso de los baños en Toledo parece que decayó bastante en el siglo XIII, tal y como deduce Torres Balbás ${ }^{50}$ de una de las Cantigas de Alfonso $\mathrm{X}$, si bien todavía en documentos del siglo Xv hay algunos baños que se siguen mencionando como referencia bien conocidas en el entramado urbano de la ciudad ${ }^{51}$.

\section{RESUMEN}

Al sur de la iglesia San Sebastián se perciben restos en los cuales se pueden ver dos baños islámicos. El baño de Suso apareció en el curso de excavaciones arqueológicas tras haber documentado unas tenerías de época posterior. En el baño

47 Boigues, C. (1989). "Los baños árabes en la ciudad de Valencia». Baños árabes en el País Valenciano. Alicante, 119-131.

48 González Palencia, A. (1930). Los mozárabes de Toledo en los siglos XII y XIII. Madrid. Doc. núm. 1162.

49 Es posible que el muro más oriental de los descubiertos hasta ahora en el conjunto del baño de Suso sea un resto de coracha que cerraba el acceso entre el barranco y el barrio de las Tenerías (fig. 10,7).

50 Torres Balbás, L. (1946): «Los baños públicos en los fueros municipales españoles». Al-Andalus, XI. 443-445.

51 Delgado Valero, C. (1987), op. cit., 392-394. Passini, J., y Molénat, J. P. (1995), op. cit., 132. 
de Yuso se han conservado tres salas abovedadas de medio cañón. Además, en la sala del poniente, identificada como sala caliente, está un arco de herradura, un ábside, y la traza de un arco geminado. El contacto entre la caldera y la sala caliente se ha conservado bajo la forma de un arco de medio punto. En el baño de Suso se han conservado el hipocausto y las toberas. Estos dos baños tienen muchas similitudes. Nos revelan, por primera vez en Toledo, el modo de calefacción de la sala caliente. Hasta el momento, no son conocidos en los documentos medievales.

\begin{abstract}
Among the archaelogical remains located to the south of San Sebastian church there are two Islamic baths. The Suso bath was discovered during an archaeological dig. Prior to that some tanneries from a later period had been found. Three chambers with barrel vaults have been preserved in the Yuso bath. Besides, in the chamber located on the western side, there are a horseshoe arch, an apse and vestiges of a twin arch. The link between the boiler and the steam room is a semicircular arch. The hypocaust and nozzles of the Suso bath have also survived. These two baths are very similar. They show, for the first time in Toledo, how the steam room was heated. There is no reference to the two baths in medieval sources.
\end{abstract}

\title{
BIBLIOGRAFÍA
}

A.C.T.E., O.F. 1016 (1572). Libro de las Posesiones del Refitor y Mesa capitular de la Santa Iglesia de Toledo de 1572.

Amador de los Ríos, R. (1905). Monumentos arquitectónicos de España. Toledo. Madrid.

Azuar Ruiz, R. (1989). «El hammam musulmán en Al-Andalus». Baños árabes en el País valenciano. Alicante.

Boigues, C. (1989). "Los baños árabes en la ciudad de Valencia». Baños árabes en el País valenciano. Alicante.

Delgado Valero, C. (1987). Toledo islámico: ciudad, arte e historia. Toledo.

González Palencia, A. (1930). Los mozárabes de Toledo en los siglos XII y XIII. Madrid.

González Simancas, M. (1929). Toledo. Sus monumentos y el arte ornamental. Madrid.

Izquierdo Benito, R. (1971). El patrimonio del Cabildo de la Catedral en el siglo $X I V$. Toledo.

Izquierdo Benito, R. (1995). «Los baños árabes de Vascos (Navalmoralejo, Toledo)». Noticiario Arqueológico Hispánico, 28.

Passini, J. (1995). «Le bain du Pozo Amargo (Tolède)». Archéologie islamique, 5: $35-46$. 
Passini, J. y J. P. Molénat (1995). Toledo a finales de la Edad Media I. El barrio de los Canónigos. Colegio Oficial de Arquitectos de Castilla-La Mancha, Delegación de Toledo, 144 p.

Paz Escribano, M. de, y Juan García, A. de (1996). «Iglesia de Santa Justa y Rufina». Toledo: arqueología en la ciudad. Patrimonio Histórico-Arqueología 13: 95110. Servicio de Publicaciones de la Junta de Comunidades de Castilla-La Mancha.

Pisa, F. de (1605). Descripción de la imperial ciudad de Toledo. Toledo, citado por Porres (1988).

Porres Martín-Cleto, J. (1988). Historia de las calles de Toledo. Ed. Zocodover, tercera edición, 3 tomos.

- (1989). Planos de Toledo. Toledo a través de sus planos. IPIET, Toledo: 35 p.

Porres Martín-Cleto, J.; R. J. Cerro Malagón; J. I. Sánchez (1991). Toledo visto por el litografo Alfred Guesdon. Inst. Provincial y Estudios Toledanos, Toledo, 103 p.

Rivas Rivas, J. C. (1982). Los baños árabes del Marquesado del Cenete. Granada, $94 \mathrm{p}$.

Torres Balbás, L. (1946). «Los baños públicos en los fueros municipales españoles». Al-Andalus, XI.

- (1959). «El baño de doña Leonor de Guzmán en el Palacio de Tordesillas». Al-Andalus, XXIV, 2: 409-425.

- (1982). "La acrópolis musulmana de Ronda». Crónica de la España Musulma$n a, 2$. 